\title{
Potential of the TROPOspheric Monitoring Instrument (TROPOMI) onboard the Sentinel-5 Precursor for the monitoring of terrestrial chlorophyll fluorescence
}

\author{
L. Guanter ${ }^{1}$, I. Aben ${ }^{2}$, P. Tol ${ }^{2}$, J. M. Krijger ${ }^{2}$, A. Hollstein ${ }^{1}$, P. Köhler ${ }^{1}$, A. Damm ${ }^{3}$, J. Joiner ${ }^{4}$, C. Frankenberg ${ }^{5}$, and \\ J. Landgraf ${ }^{2}$ \\ ${ }^{1}$ Helmholtz Centre Potsdam, German Research Center for Geosciences (GFZ), Telegrafenberg A17, \\ 14473 Potsdam, Germany \\ ${ }^{2}$ SRON Netherlands Institute for Space Research, Sorbonnelaan 2, 3584 CA Utrecht, the Netherlands \\ ${ }^{3}$ Remote Sensing Laboratories, University of Zurich, Winterthurerstrasse 190, 8057 Zurich, Switzerland \\ ${ }^{4}$ NASA Goddard Space Flight Center, Greenbelt, MD, USA \\ ${ }^{5}$ Jet Propulsion Laboratory, California Institute of Technology, Pasadena, California, USA
}

Correspondence to: L. Guanter (guanter@gfz-potsdam.de)

Received: 9 September 2014 - Published in Atmos. Meas. Tech. Discuss.: 15 December 2014

Revised: 3 March 2015 - Accepted: 4 March 2015 - Published: 19 March 2015

\begin{abstract}
Global monitoring of sun-induced chlorophyll fluorescence (SIF) is improving our knowledge about the photosynthetic functioning of terrestrial ecosystems. The feasibility of SIF retrievals from spaceborne atmospheric spectrometers has been demonstrated by a number of studies in the last years. In this work, we investigate the potential of the upcoming TROPOspheric Monitoring Instrument (TROPOMI) onboard the Sentinel-5 Precursor satellite mission for SIF retrieval. TROPOMI will sample the $675-775 \mathrm{~nm}$ spectral window with a spectral resolution of $0.5 \mathrm{~nm}$ and a pixel size of $7 \mathrm{~km} \times 7 \mathrm{~km}$. We use an extensive set of simulated TROPOMI data in order to assess the uncertainty of single SIF retrievals and subsequent spatio-temporal composites. Our results illustrate the enormous improvement in SIF monitoring achievable with TROPOMI with respect to comparable spectrometers currently in-flight, such as the Global Ozone Monitoring Experiment-2 (GOME-2) instrument. We find that TROPOMI can reduce global uncertainties in SIF mapping by more than a factor of 2 with respect to GOME-2, which comes together with an approximately 5 -fold improvement in spatial sampling. Finally, we discuss the potential of TROPOMI to map other important vegetation parameters at a global scale with moderate spatial resolution and short revisit time. Those include leaf photosynthetic pigments and
\end{abstract}

proxies for canopy structure, which will complement SIF retrievals for a self-contained description of vegetation condition and functioning.

\section{Introduction}

Sun-induced chlorophyll fluorescence (SIF) is an electromagnetic signal emitted by the chlorophyll $a$ of assimilating plants: part of the energy absorbed by chlorophyll is not used for photosynthesis, but emitted at longer wavelengths as a two-peak spectrum roughly covering the $650-850 \mathrm{~nm}$ spectral range (Porcar-Castell et al., 2014). The SIF signal originates at the cores of the photosynthetic machinery and responds instantaneously to perturbations in environmental conditions such as light and water stress, which makes it a direct proxy for photosynthetic activity. Global retrievals of SIF from space have recently been achieved from a number of spaceborne spectrometers originally intended for atmospheric research. Despite not having been designed for land applications, such instruments can provide the necessary spectral and radiometric sensitivity for SIF retrieval from space. 
The first global measurements of SIF were achieved from spectra acquired by the Japanese GOSAT mission (Joiner et al., 2011; Frankenberg et al., 2011b; Guanter et al., 2012; Joiner et al., 2012). Taking advantage of the high spectral resolution provided by GOSAT's Fourier transform spectrometer (FTS) in the 755-775 $\mathrm{nm}$ spectral window, SIF retrievals can be performed at two narrow spectral windows at 757 and $770 \mathrm{~nm}$ containing a number of solar Fraunhofer lines, which have been demonstrated to be sensitive to SIF in-filling (Frankenberg et al., 2011a). GOSAT samples the planet with individual soundings separated by several hundred kilometres, so it does not allow continuous global coverage. Complementarily, the Global Ozone Monitoring Experiment-2 (GOME-2) instruments onboard MetOp-A and MetOp-B enable SIF retrievals at $740 \mathrm{~nm}$ with a continuous global coverage, as was first demonstrated by Joiner et al. (2013) and later by Köhler et al. (2014). GOME-2 measures in the red and near-infrared (NIR) spectral regions with a spectral resolution of $\sim 0.5 \mathrm{~nm}$ and a pixel size of $\sim 40 \mathrm{~km} \times 80 \mathrm{~km}$ $(40 \mathrm{~km} \times 40 \mathrm{~km}$ for MetOp-A since July 2013). The relatively coarse spectral resolution of GOME-2 is compensated by a high radiometric sensitivity and a wide spectral coverage. Most recently, a global and spatially continuous data set of SIF retrievals at $740 \mathrm{~nm}$ has been produced from ENVISAT/SCIAMACHY by Köhler et al. (2014). Global retrievals of SIF in the $865 \mathrm{~nm}$ spectral window at the edge of the SIF spectrum were also derived from SCIAMACHY by Joiner et al. (2012).

Despite the great success represented by global spacebased SIF retrievals, the exploitation of SIF measurements for most applications is limited by the coarse spatial resolution and low number of observations, as most ecosystems are highly heterogeneous at spatial scales larger than 5-10 km and measurement noise errors are high for the comparatively low SIF signal. This issue will be greatly improved in the very near future thanks to two upcoming spaceborne spectroscopy missions: the NASA Orbiting Carbon Observatory-2 (OCO-2) (Crisp et al., 2004) and the TROPOspheric Monitoring Instrument (TROPOMI) on the Sentinel5 Precursor (Veefkind et al., 2012).

The OCO-2 mission was launched in July 2014. OCO-2 presents a spectral setting comparable to that of GOSAT, namely a very high spectral resolution spectrometer sampling the 757-775 nm spectral window with a full-width at half-maximum (FWHM) of $0.042 \mathrm{~nm}$. OCO-2 will provide a $\sim 100$-fold increase in data density with respect to GOSAT, and has a much finer spatial resolution (pixel size of $1.3 \mathrm{~km} \times 2.25 \mathrm{~km}$ ). Similar to GOSAT, this high spatial and spectral resolution comes at the expense of the global coverage, as OCO-2 does not provide full spatial mapping. The high spectral resolution of OCO-2 enables very accurate SIF retrieval approaches solely based on measurements in solar Fraunhofer lines (Frankenberg et al., 2014).

On the other hand, the Sentinel-5 Precursor mission (S5P) is an approved mission within the European Commission's
Copernicus Earth Observation Programme. S5P, scheduled for launch by the beginning of 2016, is realized by a collaboration between ESA and the Netherlands, with the European Commission also contributing to the mission operation. TROPOMI will be the single instrument payload of S5P. It is a push broom grating spectrometer combining a wide swath $(2600 \mathrm{~km})$ with high spatial resolution $(7 \mathrm{~km} \times 7 \mathrm{~km}$ at nadir) and daily global coverage. TROPOMI will perform nadir observations in the $675-775 \mathrm{~nm}$ spectral window with a spectral resolution of $0.5 \mathrm{~nm}$. According to the instrument spectral characteristics, approaches for SIF retrieval from TROPOMI can be based on the methods developed for GOME-2 and SCIAMACHY (Joiner et al., 2013; Köhler et al., 2014). However, TROPOMI's much finer spatial resolution promises to improve substantially the information content of the SIF data with respect to existing data sets, for example over fragmented agricultural areas or over tropical rainforest regions, which will especially benefit from the much higher frequency of clear-sky observations. The substantial improvements in the observational capabilities for SIF monitoring with S5P and OCO-2 with respect to GOME-2, SCIAMACHY and GOSAT are illustrated in Table 1 .

It must be remarked that TROPOMI will be the first imaging spectrometer ever to deliver global data with a moderate spatial resolution and a continuous spectral sampling of the red and NIR spectral regions (the so-called vegetation red-edge), which are also covered by GOME-2 and SCIAMACHY but with a much coarser spatial resolution. This wide spectral sampling will potentially make it possible to exploit the information carried by the full SIF spectrum and not only by the longer wavelength peak at the NIR (see Fig. 1). In addition, as will be discussed later in this work, reflectance measurements in the red-edge can be used to monitor valuable vegetation geophysical parameters complementary to SIF, which include chlorophyll content and leaf area index (LAI) as well as the directional area scattering factor (DASF) recently introduced by Knyazikhin et al. (2012). These other parameters are of great value to interpret the SIF measurements and to convert them into quantitative estimates of photosynthetic fluxes.

In this paper we present a sensitivity analysis showing the potential of TROPOMI for SIF retrieval. We select GOME-2 as a reference to evaluate TROPOMI's performance given that it provides the most similar spectral and spatial sampling (namely, $0.5 \mathrm{~nm}$ spectral resolution, wide spectral window and continuous spatial sampling). The paper is structured as follows: Sect. 2 describes the fundamentals of the SIF retrieval method selected for our sensitivity study. Section 3 describes the TROPOMI and GOME-2 simulations used in the analysis. Section 4 presents the results with emphasis on the comparison between TROPOMI and GOME-2. The validation of the TROPOMI SIF retrievals through the comparison with OCO-2 retrievals and the potential of TROPOMI for the monitoring of other vegetation parameters are discussed 
Table 1. Relevant characteristics of current and near-future satellite missions enabling SIF retrievals. The improvement in spatial resolution and number of clear-sky observations per day from Sentinel-5 Precursor/TROPOMI are highlighted with *. NIR stands for near-infrared. It must be noted that GOME-2 on MetOp-A has been operating in a reduced-swath mode since 15 July 2013 with a reduced pixel size of $40 \times 40 \mathrm{~km}^{2}$.

\begin{tabular}{|c|c|c|c|c|c|}
\hline & GOSAT & GOME-2 & SCIAMACHY & OCO-2 & TROPOMI \\
\hline Data since/from & Jun 2009 & Jan 2007 & 2002-2012 & Aug 2014 & Mid 2016 \\
\hline Overpass time & Midday & Morning & Morning & Midday & Midday \\
\hline Red/NIR spectral coverage & $757-775 \mathrm{~nm}$ & $650-790 \mathrm{~nm}$ & $650-790 \mathrm{~nm}$ & $757-775 \mathrm{~nm}$ & $675-775 \mathrm{~nm}$ \\
\hline Spectral resolution at $750 \mathrm{~nm}$ & $\sim 0.025 \mathrm{~nm}$ & $\sim 0.5 \mathrm{~nm}$ & $\sim 0.5 \mathrm{~nm}$ & $\sim 0.05 \mathrm{~nm}$ & $\sim 0.5 \mathrm{~nm}$ \\
\hline Type of spatial sampling & Sparse & Continuous & Continuous & Sparse & Continuous \\
\hline $\begin{array}{l}\text { Spatial resolution of } \\
\text { single measurements }\end{array}$ & $10 \mathrm{~km}$ diam. & $40 \times 80 \mathrm{~km}^{2}$ & $30 \times 240 \mathrm{~km}^{2}$ & $1.3 \times 2.25 \mathrm{~km}^{2}$ & $7 \times 7 \mathrm{~km}^{2 *}$ \\
\hline $\begin{array}{l}\text { Typical resolution of } \\
\text { global composites }\end{array}$ & $2^{\circ}$ & $0.5^{\circ}$ & $1.5^{\circ}$ & $1^{\circ}$ & $0.1^{\circ *}$ \\
\hline $\begin{array}{l}\text { Approx. number of NIR clear-sky } \\
\text { observations over land per day }\end{array}$ & 600 & 2800 & 900 & $\sim 129900$ & $\sim 544300^{*}$ \\
\hline
\end{tabular}

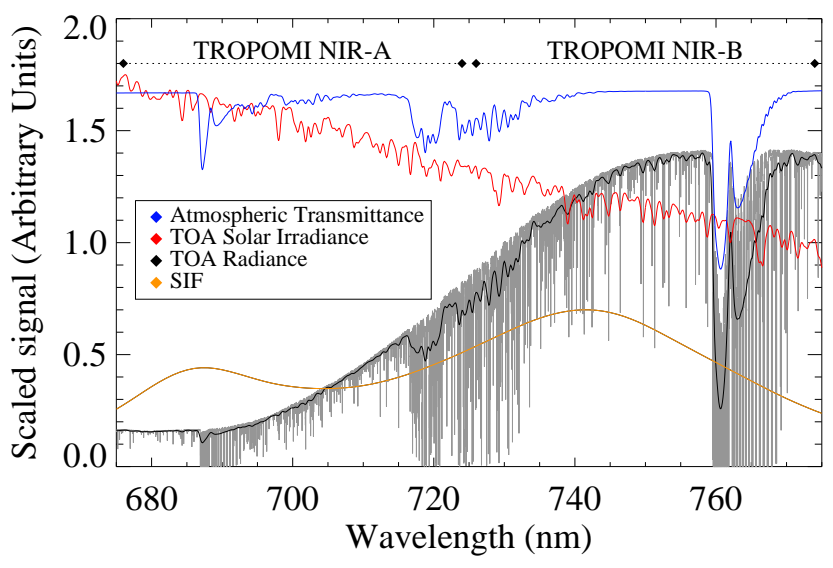

Figure 1. Normalized spectra of sun-induced fluorescence (SIF), atmospheric transmittance, solar irradiance at the top-of-atmosphere (TOA) and TOA radiance from a green vegetation target. The spectra are presented at the $0.1 \mathrm{~nm}$ spectral sampling and $0.5 \mathrm{~nm}$ resolution of TROPOMI. The TOA radiance spectrum is also plotted at $0.005 \mathrm{~nm}$ resolution (grey shading).

in Sect. 5. The main findings of the study are summarized in Sect. 6 .

\section{SIF retrieval from space}

\subsection{In-filling of solar Fraunhofer lines by SIF}

The remote estimation of SIF based on the in-filling of solar Fraunhofer lines in high spectral resolution spectra was first proposed by Plascyk and Gabriel (1975), whereas its applicability to the satellite scale was demonstrated in simulations by Sioris et al. (2003) and Frankenberg et al. (2011a). The SIF emission is a spectrally smooth signal superimposed on the solar radiation reflected and transmitted by the Earth's surface and atmosphere. Due to the additive nature of SIF on the solar radiation, the fractional depth of the Fraunhofer lines in the solar spectrum decreases in the presence of SIF (Plascyk and Gabriel, 1975).

The first global retrievals of SIF exploited the high spectral resolution of the GOSAT FTS to evaluate the in-filling of Fraunhofer lines by SIF (Joiner et al., 2011; Frankenberg et al., 2011b; Guanter et al., 2012; Joiner et al., 2012). The retrieval model is fairly simple in this case, as only individual lines within narrow spectral windows devoid of atmospheric absorption are considered. However, for measurements with a coarser spectral resolution, such as those of GOME-2 or TROPOMI, the Fraunhofer lines interfere with atmospheric absorption lines in the spectrum. This is illustrated in Fig. 1. Only the spectral windows $675-685$ and $745-758 \mathrm{~nm}$, and to some extent $710-715 \mathrm{~nm}$, can be considered free from atmospheric absorption feature and therefore enable a pure Fraunhofer line-based retrieval (GOSAT-like). Depending on the instrument signal-to-noise ratio (SNR) and spectral resolution, however, these spectral windows may not contain a sufficient number of spectral measurements to achieve the required measurement precision. For example, Joiner et al. (2013) used a fitting window from 712 to $783 \mathrm{~nm}$ for the first retrievals from GOME-2. The retrieval model becomes more complicated for such wider fitting windows, as both the spectrally smooth surface reflectance and atmospheric scattering and absorption must be modelled as well.

\subsection{Retrieval approach: data-driven modelling of atmospheric transmittance and solar irradiance}

The monochromatic radiance measured by a sensor at the top-of-atmosphere (TOA) over a fluorescent target with a reflectance assumed to be Lambertian can be formulated as 
$L_{\mathrm{TOA}}=\frac{\mu_{\mathrm{s}} I_{\mathrm{sc}}}{\pi}\left[\rho_{0}+\frac{\rho_{\mathrm{s}} T_{\downarrow \uparrow}}{1-S \rho_{\mathrm{s}}}\right]+\frac{F_{\mathrm{s}} T_{\uparrow}}{1-S \rho_{\mathrm{s}}}$,

where $\rho_{\mathrm{S}}$ is the surface reflectance, $\rho_{0}$ the atmospheric path reflectance, $T_{\downarrow \uparrow}\left(T_{\uparrow}\right)$ the two-way (ground to sensor) total atmospheric transmittance, $S$ the atmospheric spherical albedo, $\mu_{\mathrm{s}}$ the cosine of the sun zenith angle (SZA), $I_{\mathrm{sc}}$ the TOA solar irradiance, and $F_{\mathrm{S}}$ monochromatic SIF. In order to estimate $F_{\mathrm{s}}$ from $L_{\mathrm{TOA}}$, an accurate modelling of atmospheric radiative transfer ( $\rho_{0}, T_{\downarrow \uparrow}, S$ and $T_{\uparrow}$ parameters), the solar irradiance $I_{\mathrm{sc}}$ and surface reflectance $\rho_{\mathrm{s}}$ are needed.

In our retrieval model, the spectrally smooth terms, including $\rho_{\mathrm{S}}$ and scattering-related contributions in $\rho_{0}$ and $S$, are represented by a polynomial of order $n$. The $I_{\mathrm{sc}}$ can be known with a relatively high accuracy from either solar irradiance measurements acquired by the instrument itself during calibration operations or from external solar spectrum measurements (e.g. Chance and Kurucz, 2010). Regarding $T_{\downarrow \uparrow}$, small uncertainties in atmospheric radiative transfer modelling with full-physics approaches (e.g. from model simplifications or uncertainty in input parameters) would lead to large errors in SIF (Guanter et al., 2010; Frankenberg et al., 2011a; Sanders and de Haan, 2013). Therefore, here we use a data-driven approach (as opposed to full-physics) following Joiner et al. (2013). Atmospheric transmittance is modelled by means of a set of orthogonal spectral functions derived from measured spectra through principal component analysis.

Under these considerations, we can define the following forward model $(\boldsymbol{F})$ to model the measured TOA radiance spectra:

$\boldsymbol{F}\left(\boldsymbol{a}, \boldsymbol{\alpha}, F_{\mathrm{S}}\right)=\left(\sum_{i=0}^{n_{\mathrm{p}}} a_{i} \lambda^{i}\right) \cdot\left(\sum_{j=1}^{n_{\mathrm{V}}} \alpha_{j} \boldsymbol{v}_{j}\right)+F_{\mathrm{s}} \boldsymbol{h}_{\mathrm{F}} \cdot \boldsymbol{T}_{\uparrow}^{\mathrm{e}}$,

where $\lambda$ is the array of measurement wavelengths used for the representation of spectrally smooth terms such as surface reflectance and atmospheric scattering, $\boldsymbol{v}$ is the basis of principal components describing the variability in solar irradiance and atmospheric transmittance $\left(\sum_{j=1}^{n_{\mathrm{v}}} \alpha_{j} \boldsymbol{v}_{j} \sim \boldsymbol{I}_{\mathrm{sc}} \cdot \boldsymbol{T}_{\downarrow \uparrow}\right)$, $F_{\mathrm{S}}$ is SIF at a given reference wavelength (normally the centre of the fitting window), $\boldsymbol{h}_{\mathrm{F}}$ is a fixed spectral function normalized at the reference wavelength, which accounts for the spectral shape of SIF, $\boldsymbol{T}_{\uparrow}^{\mathrm{e}}$ is an effective upward transmittance, $n_{\mathrm{p}}$ is the order of the polynomial used to represent spectrally smooth terms, and $n_{\mathrm{v}}$ is the number of principal components representing high spectral frequency variations in $\boldsymbol{I}_{\mathrm{sc}} \cdot \boldsymbol{T}_{\downarrow \uparrow}$, where the $\cdot$ symbol represents an element-wise product of vectors.

The state vector elements are $\boldsymbol{a}, \boldsymbol{\alpha}$, and $F_{\mathrm{s}}$, whereas $\lambda$, $\boldsymbol{v}, \boldsymbol{h}_{\mathrm{F}}$ and $\boldsymbol{T}_{\uparrow}^{\mathrm{e}}$ are model parameters. Regarding these, $\boldsymbol{\lambda}$ is known for each spectrum, $\boldsymbol{v}$ is derived from principal component analysis of real measurements as described in Joiner et al. (2013) and Köhler et al. (2014), and the spectral function $\boldsymbol{h}_{\mathrm{F}}$ can be extracted from spectral libraries, which is justified in Guanter et al. (2013). As for $\boldsymbol{T}_{\uparrow}^{\mathrm{e}}$, we estimate it from an effective $\boldsymbol{T}_{\downarrow \uparrow}$, which is derived from the normalization of the measured radiance spectra by $\boldsymbol{I}_{\mathrm{sc}}$ (convolved by the instrument spectral response function) and the spectral continuum. Although $\boldsymbol{T}_{\uparrow}^{\mathrm{e}}$ differs slightly from the real $\boldsymbol{T}_{\uparrow}$ over vegetated areas due to the in-filling of atmospheric lines by SIF, we assume that this effect is negligible because most of the information for the retrieval is provided by the Fraunhofer lines.

It must be remarked that the estimation of atmospheric transmittance from TOA radiance spectra normalized by the continuum implies that $\boldsymbol{T}_{\downarrow \uparrow}$ and hence $\boldsymbol{T}_{\uparrow}^{\mathrm{e}}$ are normalized to 1 in continuum regions. Therefore, neither $\sum_{j=1}^{n_{\mathrm{v}}} \alpha_{j} \boldsymbol{v}_{j}$ nor $\boldsymbol{T}_{\uparrow}^{\mathrm{e}}$ take into account varying atmospheric absorption in the continuum. This can low-bias the retrieval for e.g. tilted illumination/observation geometries and high atmospheric optical thickness like in the presence of clouds.

Following Guanter et al. (2013), the forward model in Eq. (2) is further simplified so that the number of state vector elements is reduced in order to minimize the risk of overfitting. This is achieved by only convolving the most significant of the $v$ with the polynomial in wavelength, leading to

$$
\boldsymbol{F}^{\prime}\left(\boldsymbol{a}, \boldsymbol{\alpha}, F_{\mathrm{S}}\right)=\boldsymbol{v}_{1} \sum_{i=0}^{n_{\mathrm{p}}} a_{i} \lambda^{i}+\sum_{j=2}^{n_{\mathrm{v}}} \alpha_{j} \boldsymbol{v}_{j}+F_{\mathrm{S}} \boldsymbol{h}_{\mathrm{F}} \cdot \boldsymbol{T}_{\uparrow}^{\mathrm{e}},
$$

which is the final form of the forward model used for the sensitivity analysis presented in this work. It has a total of $n_{\mathrm{p}}+n_{\mathrm{v}}+1$ elements to be inverted. We set $n_{\mathrm{p}}$ to values between 2 and 4 depending on the width of the fitting window, whereas an ad hoc threshold of $0.05 \%$ on the percentage of the variance of the training set explained by each singular vector is used to select $n_{\mathrm{v}}$. It typically takes values between 4 and 10 depending on the width of the fitting window and the amount of solar and atmospheric lines contained in it.

\subsection{Retrieval random error}

The retrieval error covariance matrix $\mathbf{S}_{\mathrm{e}}$ is given by

$\mathbf{S}_{\mathrm{e}}=\left(\mathbf{J}^{T} \mathbf{S}_{0}^{-1} \mathbf{J}\right)^{-1}$,

where $\mathbf{S}_{0}$ is the measurement error covariance matrix (in our case, only instrumental noise in the measurement) and $\mathbf{J}$ is the Jacobian matrix consisting of the terms $\mathbf{J}\left(a_{i}\right)=\boldsymbol{v}_{1} \lambda^{i}$, $\mathbf{J}\left(\alpha_{j}\right)=\boldsymbol{v}_{j}$ and $\mathbf{J}\left(F_{\mathrm{S}}\right)=\boldsymbol{h}_{\mathrm{F}} \boldsymbol{T}_{\uparrow}^{\mathrm{e}}$. The diagonal of the $\mathbf{S}_{\mathrm{e}}$ matrix contains the random error of the retrieved state vector elements $\left(\boldsymbol{a}, \boldsymbol{\alpha}, F_{\mathrm{s}}\right)$. Because of the linear nature of the forward model, the Jacobian functions do not depend on the state vector elements, but only on model parameters. The only model parameter that changes for each measured spectrum is $\boldsymbol{T}_{\uparrow}^{\mathrm{e}}$, but it is generally close to 1 for fitting windows devoid of strong atmospheric lines. 
As a result, the retrieval random error only depends on measurement noise and a set of scalars. For photonnoise driven instruments such as GOME-2, SCIAMACHY or TROPOMI, the measurement noise scales with the square root of the incoming at-sensor radiance, and so does the single-retrieval $1 \sigma$ error. Therefore, the retrieval precision is lower for bright areas and high illumination levels. This may be counterintuitive, as the measurement SNR is maximized for those measurements conditions. This finding will be further discussed in Sect. 4.1.

\section{Simulation setup and sensitivity analysis}

We have simulated a large ensemble of TROPOMI-like spectra in order to estimate retrieval uncertainties (precision and accuracy) for different retrieval configurations. We have also simulated the global distribution of instrumental noise and total number of clear-sky observations for typical acquisition scenarios with the purpose of investigating the uncertainty of spatio-temporal composites of SIF retrievals from TROPOMI. We have also done the simulations for GOME-2 for intercomparison with TROPOMI. GOME-2 is chosen because it is the instrument with the most similar spectral and spatial sampling characteristics to TROPOMI.

\subsection{Spectrum-based simulations}

Our spectrum-based simulations comprise surface and atmospheric models common to TROPOMI and GOME-2 as well as sensor-specific instrumental models. The surface model consists of a set of top-of-canopy (TOC) reflectance and SIF spectra $(500-800 \mathrm{~nm})$ derived with the FluorSAIL leaf+canopy radiative transfer model (Miller et al., 2005) from a combination of four values of chlorophyll content (Cab) $\left(5,10,20,40 \mu \mathrm{g} \mathrm{cm}^{-2}\right)$ and five values of LAI $(0.5$, $1,2,3,4)$. The resulting $20 \mathrm{SIF}$ spectra were in turn scaled by a factor of 2 chosen arbitrarily in order to extend the range of SIF values covered by the simulations. This gives a total of 20 reflectance and 40 SIF spectra. Exemplary TOC reflectance and SIF spectra from four combinations of $\mathrm{Cab}$ and LAI are displayed in Fig. 2.

The resulting TOC reflectance and SIF spectra were converted into TOA radiance spectra following Eq. (1). The atmospheric radiative transfer simulations consisted of two temperature profiles (mid-latitude summer and mid-latitude winter), five aerosol optical thicknesses at $550 \mathrm{~nm}(0.05$, $0.12,0.20,0.30,0.40)$, three aerosol heights $(600,700$, and $800 \mathrm{hPa}$ ), a fixed continental aerosol model, four surface pressure values $(955,980,1005$, and $1030 \mathrm{hPa})$, four water vapour column contents $\left(0.5,1.5,2.5,4.0 \mathrm{~g} \mathrm{~cm}^{-2}\right)$, two view zenith angles ( 0 and $15^{\circ}$, simulating quasinadir observations) and four sun zenith angles (15, 30, 45, $70^{\circ}$ ). Simulations were performed with the Matrix Operator Model (MOMO) radiative transfer code (Fell and Fischer,

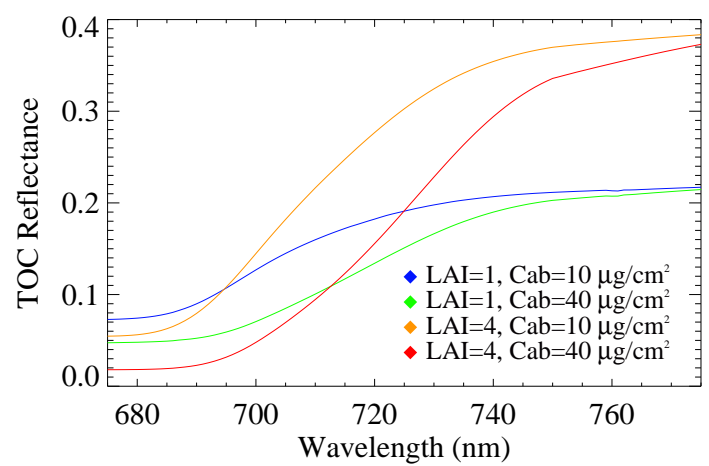

(a)

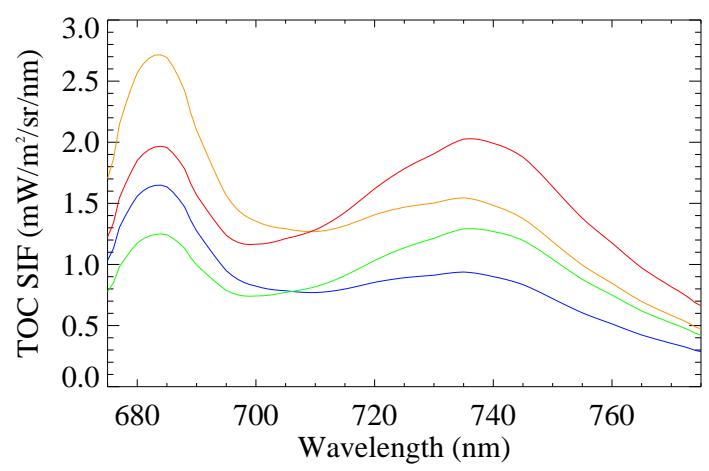

(b)

Figure 2. Top-of-canopy (TOC) surface reflectance (a) and SIF (b) spectra as a function of leaf area index (LAI) and chlorophyll content $(\mathrm{Cab})$ in the $675-775 \mathrm{~nm}$ spectral range covered by the NIR-A and NIR-B spectral bands of TROPOMI.

2001), run monochromatically with a spectral sampling of $0.005 \mathrm{~nm}$. The combination of this ensemble of 3840 atmospheric conditions with the 40 surface cases leads to total of 153600 simulated TOA radiance spectra. This simulated data set is to a large extent consistent with the one used in Joiner et al. (2013) and Köhler et al. (2014).

Concerning the instrument model, a Gaussian spectral response function with a $0.5 \mathrm{~nm}$ FWHM is used for both TROPOMI and GOME-2. The spectral sampling interval (SSI) is $0.1 \mathrm{~nm}$ for TROPOMI and $0.2 \mathrm{~nm}$ for GOME-2. Instrumental noise is added on the spectra as Gaussian, spectrally uncorrelated noise after spectral convolution. Input curves of SNR vs. radiance at $758 \mathrm{~nm}$ are used for this purpose. The SNR curve for GOME-2 was provided by EUMETSAT (R. Lang, EUMETSAT, personal communication, 2014). Due to the lack of more detailed information, the SNR of TROPOMI is simulated according to the mission requirement that $\mathrm{SNR}=500$ at $758 \mathrm{~nm}$ for $L_{\mathrm{TOA}}=4.5 \times 10^{12}$ photons s${ }^{-1} \mathrm{~cm}^{-2} \mathrm{sr}^{-1} \mathrm{~nm}^{-1}$, as 


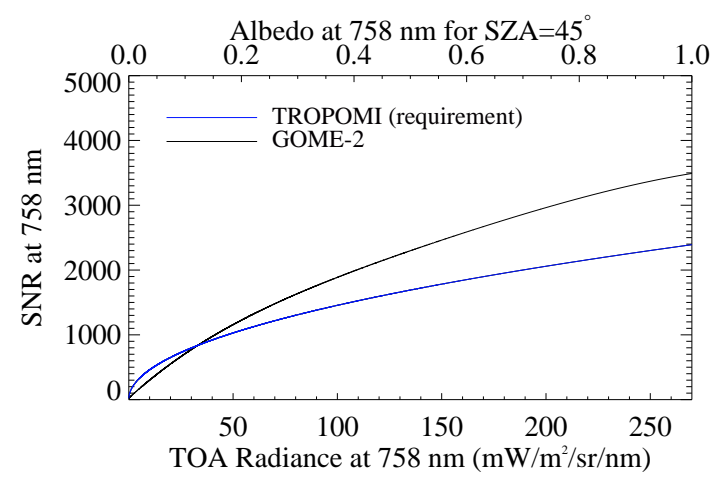

Figure 3. Curves of signal-to-noise ratio (SNR) versus top-ofatmosphere radiance at $758 \mathrm{~nm}$ for GOME-2 and TROPOMI. The SNR curve for TROPOMI is derived with Eq. (5) and reflects mission requirements. It represents a lower boundary for the actual TROPOMI SNR.

$\operatorname{SNR}(\lambda)=500 \sqrt{\frac{L_{\mathrm{TOA}}(\lambda)}{4.5 \times 10^{12}}}$,

based on Sanders and de Haan (2013). The SNR-radiance curves for TROPOMI and GOME-2 are displayed in Fig. 3. The mean and standard deviation of the simulated TROPOMI TOA radiance spectra as well as the spectral SNR calculated from the mean radiance spectrum of the TROPOMI simulations are plotted in Fig. 4.

We would like to state that our simplified noise modelling for TROPOMI and GOME-2 based on SNR-radiance curves neglects radiance-independent contributions to the total measurement noise (e.g. dark current or read-out noise), which might affect our simulations at low signal levels, such as at $690 \mathrm{~nm}$ for the largest illumination angles. In general, we consider that this should not have a significant impact at longer wavelengths, as vegetation reflectance grows quickly in the far-red. It must also be stated that the actual SNR expected for TROPOMI largely exceeds that in Fig. 3 solely based on mission requirements. Therefore, uncertainties in both SNR-radiance curves and the partitioning between multiplicative and additive contributions limit our capability for robust quantitative estimates of retrieval uncertainty from TROPOMI. Finally, we acknowledge that no systematic radiometric errors, such as from calibration offsets or stray light, are included in our instrument model. This implies that our estimates of retrieval accuracy may overestimate the real accuracy.

This data set of clear-sky spectra has been completed with another set of MOMO simulations providing the same atmospheric optical parameters in Eq. (1) but for a range of cloud optical thickness (COT, at $550 \mathrm{~nm}$ ) values from 0.1 to 10 . This is used to investigate the effect of clouds on the retrieval. We restricted ourselves to the case of clouds with liquid droplets with a fixed vertical profile and a cloud droplet effective radius of $15 \mu \mathrm{m}$.

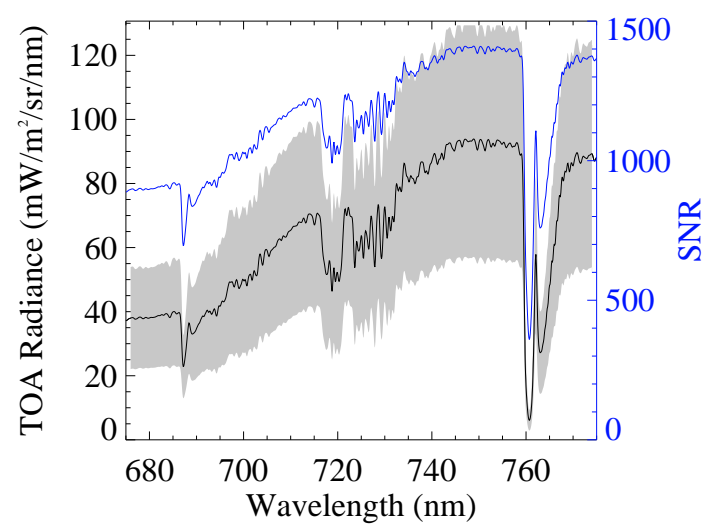

Figure 4. TROPOMI-like top-of-atmosphere (TOA) spectral radiance and signal-to-noise ratio (SNR). The black curve depicts the mean from the 153600 simulated TOA spectra, and the shaded area shows the standard deviation. The SNR estimated from the mean TOA radiance spectrum and the TROPOMI SNR curve in Fig. 3 is plotted in blue.

\subsection{Global simulations}

We have assessed the precision of data composites produced through the spatio-temporal binning of single clear-sky SIF retrievals. The precision of those binned SIF retrievals is represented by the standard error of the mean $\sigma$,

$\sigma(\overline{\mathrm{SIF}})=\frac{1}{\sqrt{\sum_{i=1}^{n_{\mathrm{m}}}\left(1 / \sigma_{i}\right)^{2}}}$,

where $\overline{\mathrm{SIF}}$ is the mean value of the $n_{\mathrm{m}}$ clear-sky retrievals in a given gridbox and time window, and $\sigma_{i}$ is the single-retrieval $1 \sigma$ precision provided by Eq. (4).

Instrumental noise is calculated for each gridbox as a function of TOA radiance with the SNR- $L_{\text {TOA }}$ curves in Fig. 3. $L_{\mathrm{TOA}}$ is calculated gridbox-wise as a function of spectral surface albedo and cos(SZA). Surface albedo is calculated from the red and NIR reflectance bands of the MODIS MOD13C2 product (Huete et al., 2002), which are interpolated to cover the entire $600-800 \mathrm{~nm}$ spectral range. The MODIS-enhanced vegetation index (EVI), also included in the MOD13C2 product, is used to represent global distributions of SIF. EVI is modulated by $\cos (\mathrm{SZA})$ in order to indicate the dependence of SIF on incoming radiation. $\mathrm{EVI} \times \cos (\mathrm{SZA})$ is scaled to realistic SIF values by means of an arbitrary factor of 3.5 selected through the comparison of real EVI $\times \cos (\mathrm{SZA})$ and SIF data sets. A spatial grid of $0.1^{\circ}$ is used to aggregate the TROPOMI $7 \mathrm{~km} \times 7 \mathrm{~km}$ measurements, whereas a grid of $0.5^{\circ}$ is used for GOME-2 for consistency with previous studies (Joiner et al., 2013; Köhler et al., 2014).

Concerning the estimation of the number of clear-sky observations per gridbox $n_{\mathrm{m}}$, we have combined cloud statistics with estimates of the average number of overpasses per day, 


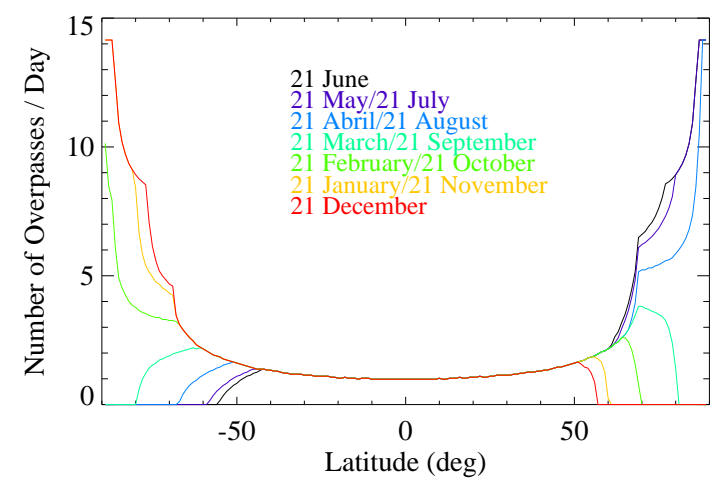

Figure 5. Average number of overpasses per day by TROPOMI as a function of latitude and month. The calculations are for $\mathrm{SZA}<80^{\circ}$, a sun-synchronous orbit and 13:30 h equatorial crossing time as appropriate for Sentinel-5 Precursor.

latitude and month for TROPOMI and GOME-2 (displayed for TROPOMI in Fig. 5). As for cloud statistics, we have used the cloud fraction data described in Krijger et al. (2007). Global cloud fraction data are derived from the MODIS Aqua $\sim 1 \mathrm{~km} \times 1 \mathrm{~km}$ Level 2 Cloud Mask product (MYD35, collection 004).

It must be stated that in this simulation we neglect potential directional effects on the SIF emission (Joiner et al., 2012; Guanter et al., 2012), as all the retrievals in a given spatio-temporal bin are averaged irrespective of the observation geometry. The combination of retrievals from different observation angles can cause additional variability and/or offsets in the mean values which are not considered in this study. Such an effect can be especially relevant for TROPOMI, as its wide swath will lead to a wider range of view angles than existing instruments. On the other hand, we do not expect observation angles to have a notable effect on the single-retrieval accuracy, since the viewing and illumination geometries do not affect the fractional depth of Fraunhofer lines.

\section{Results}

\subsection{Estimates of retrieval precision and accuracy}

Results of end-to-end simulations of SIF retrievals in the $735-758 \mathrm{~nm}$ window from the 153600 TOA radiance spectra described in Sect. 3.1 are displayed in Fig. 6. Each point corresponds to one of the 40 surface cases (combinations of $\mathrm{Cab}$, LAI and SIF intensity) used for the simulations. Diamond symbols and error bars for each of those points represent, respectively, the mean and standard deviation from the retrievals for all the atmospheric conditions and illumination/observation angles. The retrieval simulations were performed with and without including instrumental noise in order to illustrate the impact of noise on the retrieval.

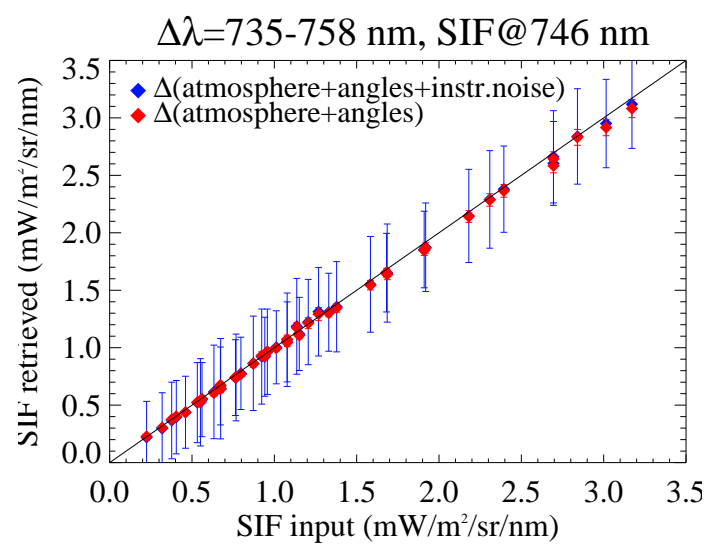

Figure 6. End-to-end simulations of SIF retrieval from TROPOMI in the $735-758 \mathrm{~nm}$ fitting window for a total of 153600 TOA radiance spectra. Diamond symbols and error bars represent, respectively, the mean and standard deviation of all the retrievals for each vegetation type and range of atmospheric conditions and illumination/observation angles. The simulations are done either with or without instrumental noise (error bars for the noise-free case are mostly invisible).

The $735-758 \mathrm{~nm}$ window is chosen as the reference fitting window hereinafter in our study. It provides a relatively high number of spectral points in a spectral region devoid of strong atmospheric absorption lines (see Fig. 1), while the modelling of the spectral continuum can be achieved with a low-order polynomial. Wider fitting windows would provide a higher number of spectral measurements (hence higher precision), but the modelling of the spectral continuum by a polynomial would become more difficult due to non-linear reflectance around the vegetation spectral red-edge, which could lead to biases in the retrieval. The retrieval would also be complicated for wider fitting windows by the interaction with atmospheric absorption and scattering.

Figure 6 shows that, for this controlled simulated setup, the retrieval is not biased for any of the 20 vegetation reflectance spectra tested (high retrieval accuracy). On the other hand, the very small error bars for the noise-free case illustrates the low sensitivity of the retrieval to varying atmospheric conditions and illumination/observation geometries, which serves as a test of consistency for our data-driven atmospheric modelling approach. Finally, the comparison with the simulations including instrumental noise shows that noise is the main driver of the retrieval error if other sources of systematic errors such as radiometric offsets or stray light are neglected.

The retrieval precision has been investigated more indepth. Instrumental noise has been propagated to $1 \sigma$ random uncertainty in SIF retrieval by means of Eq. (4) and different configurations of the forward model in Eq. (3). Results are presented in Fig. 7. Figure 7a depicts the $1 \sigma$ single-retrieval error for TROPOMI as a function of At-sensor radiance at $758 \mathrm{~nm}$ (represented as variable surface albedo at $758 \mathrm{~nm}$ for a constant $\mathrm{SZA}=45^{\circ}$ ) and the width of the fitting window. 


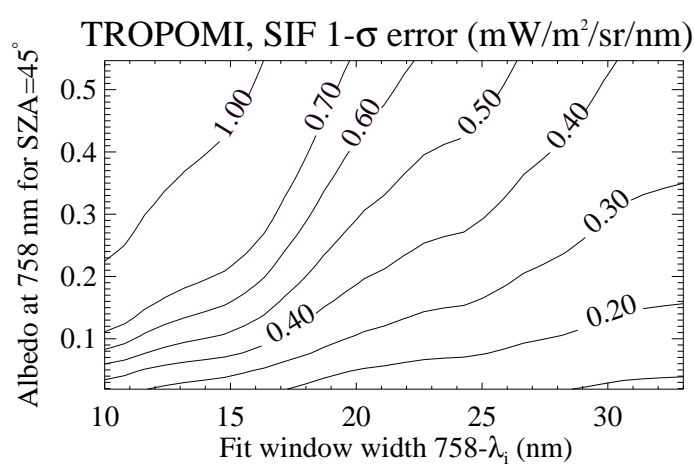

(a)

TROPOMI vs GOME-2, $\Delta \lambda=735-758 \mathrm{~nm}$

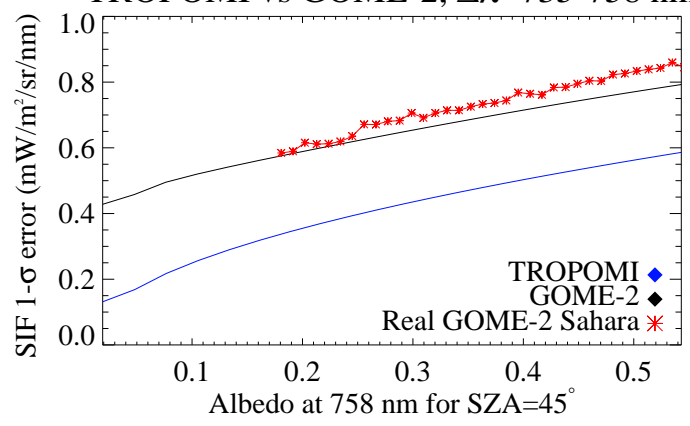

(b)

Figure 7. Simulated precision of SIF retrieval from TROPOMI as a function of surface albedo at $758 \mathrm{~nm}$ for the reference sun zenith angle (SZA) of $45^{\circ}$. The dependence on the width of the spectral fitting window in the range between 725 and $758 \mathrm{~nm}$ is displayed in (a), and the comparison with GOME-2 for the 735-758 nm fitting window is shown in (b). The standard deviation calculated from real GOME-2 SIF retrievals in the same fitting window over the Sahara desert $\left(15-30^{\circ} \mathrm{N},-5-30^{\circ} \mathrm{E}\right)$ is also plotted.

As expected, the retrieval precision increases with the fitting window width, as more measurements become available for the fit. It can also be observed in Fig. 7 that precision decreases with surface albedo (equivalent to TOA radiance), as discussed in Sect. 2.3. This is also visible in Fig. 6, where the larger error bars correspond to surface cases with high LAI as this is the main driver of vegetation NIR surface albedo (Fig. 2a).

The sensitivity of TROPOMI and GOME-2 spectral measurements for SIF retrieval is illustrated in Fig. 7b, which shows the $1 \sigma$ uncertainty from TROPOMI and GOME- 2 retrievals as a function of surface albedo at $758 \mathrm{~nm}$ for the particular case of a fitting window between 735 and $758 \mathrm{~nm}$. The sensitivity of TROPOMI is systematically higher than that of GOME-2, which is mostly given by the double number of spectral measurements because of the $0.1 \mathrm{~nm} \mathrm{SSI}(0.2 \mathrm{~nm}$ for GOME-2). It must be noted, though, that these are estimates of single-retrieval precision. The difference in the uncertainty from the two instruments is much larger for averages of single retrievals in spatio-temporal bins, as TROPOMI performs 216 measurements in $1 \mathrm{~s}$ with $7 \mathrm{~km} \times 7 \mathrm{~km}$ spatial resolution and GOME- 2 has four measurements in $1 \mathrm{~s}$ with $80 \mathrm{~km} \times 40 \mathrm{~km}$.

Figure $7 \mathrm{~b}$ also includes the standard deviation of SIF retrievals from real GOME-2 spectra acquired in 2010 over the Sahara desert (defined by the latitude-longitude box $15^{\circ}-$ $30^{\circ} \mathrm{N},-5-30^{\circ} \mathrm{E}$ ). Retrievals were performed in the $735-$ $758 \mathrm{~nm}$ fitting window with the method described in Joiner et al. (2013). At-sensor radiance at $758 \mathrm{~nm}$ has been converted to an equivalent surface albedo at $\mathrm{SZA}=45^{\circ}$ for representation purposes. Since we do not expect any significant variability in SIF over that area, we assume that the standard deviation of single retrievals can represent the theoretical $1 \sigma$ retrieval uncertainty. The results from real GOME- 2 data show a close agreement with the $1 \sigma$ uncertainty simulated for GOME-2 despite the slightly different forward models used for the simulations and the retrievals from real data. This result reinforces the confidence in our simulation approach and serves as an empirical demonstration of the counterintuitive fact that retrieval precision decreases with TOA radiance as discussed in Sect. 2.3.

End-to-end retrieval simulation results for several fitting windows are displayed in Fig. 8. The $725-758 \mathrm{~nm}$ window in Fig. 8a samples the second peak of the SIF spectrum. It is a wide spectral window containing a large number of Fraunhofer lines as well as some water vapour lines in 725$740 \mathrm{~nm}$. Retrieval precision is high due to the large number of spectral measurements, although small deviations from the $1: 1$ line are also observed. These are most likely due to difficulties to model smooth non-linear spectral variations by the polynomial in wavelength in the forward model (Eq. 3). Oppositely, the $745-758 \mathrm{~nm}$ case in Fig. $8 \mathrm{~b}$ represents a pure Fraunhofer line-based retrieval, as this window contains no atmospheric lines (see Fig. 1). The retrieval for this narrow fitting window is very accurate, which is mostly due to the simpler modelling of the spectral continuum discussed above. The sensitivity to noise for this fitting window is relatively high because of the lower amount of spectral points. As previously discussed, the window $735-758 \mathrm{~nm}$ in Fig. 6 is selected as the best compromise between precision and window width.

The longer-wavelength part of the SIF spectrum is sampled by the 745-772 $\mathrm{nm}$ window containing the $\mathrm{O}_{2}$ A-band (Fig. 8c). Despite the complexity of modelling atmospheric transmittance inside the $\mathrm{O}_{2}$ A-band, the results in Fig. 8c confirm that our retrieval approach can also be applied in that spectral range, which is relevant for instruments in which NIR measurements are restricted to the $\mathrm{O}_{2}$ A-band.

Results for fitting windows sampling the first peak of the SIF spectrum are presented in Fig. 8d-f. Non-negligible systematic errors are observed for all three fitting windows, which can be attributed to both interference of atmospheric absorption lines and errors in the representation of non-linear surface reflectance by the forward model (the case of the 


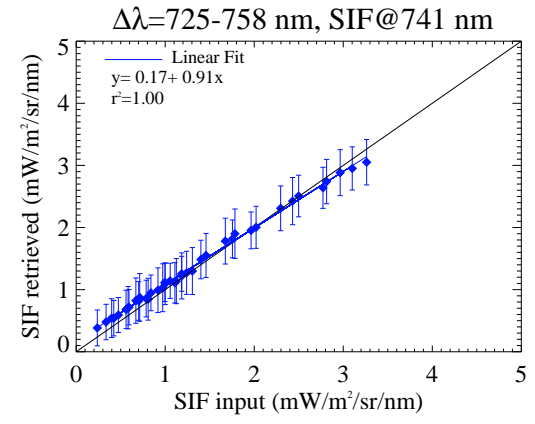

(a)

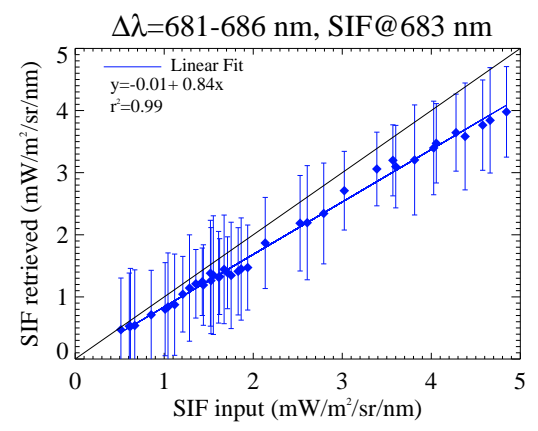

(d)

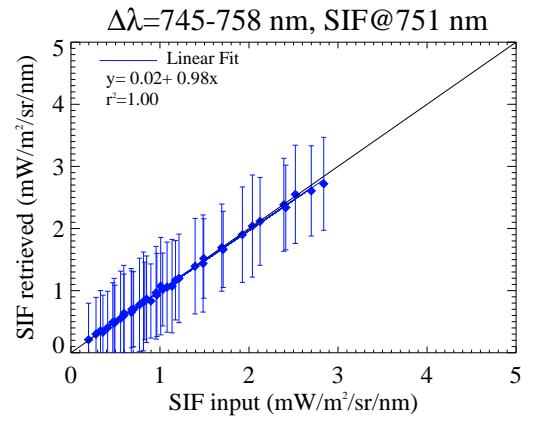

(b)

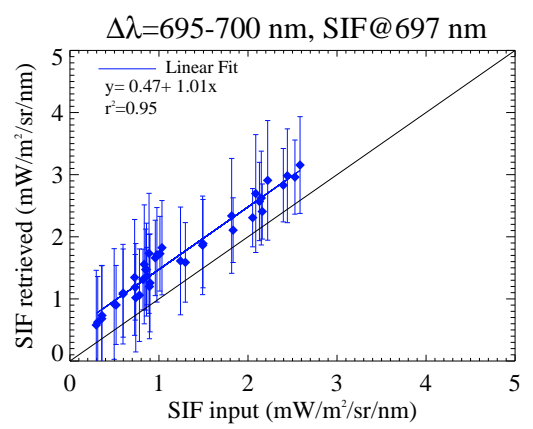

(e)

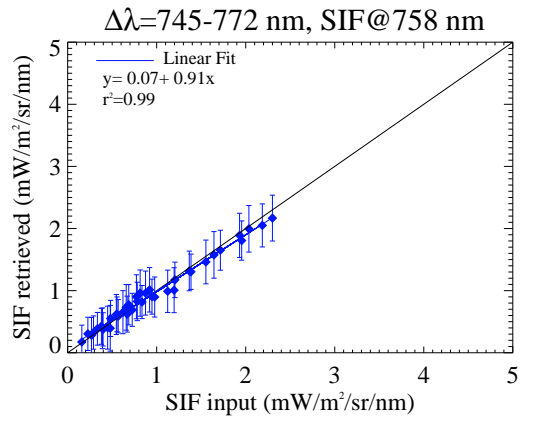

(c)

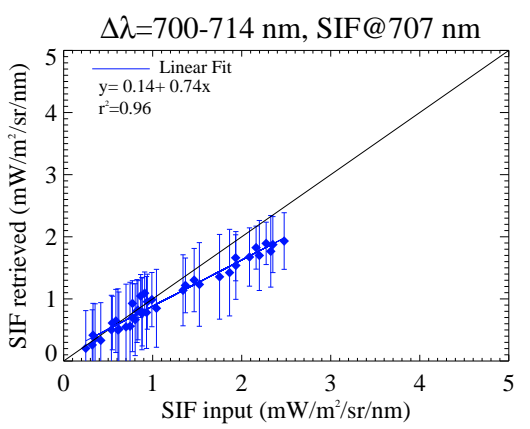

(f)

Figure 8. Similar to Fig. 6, but for different spectral fitting windows sampling the two peaks of the SIF emission. Simulations include instrumental noise. All the plots have the same axes.

681-686 nm window, devoid of atmospheric lines). However, despite those biases we consider these results to be of high interest, as they show the feasibility of red SIF retrievals from TROPOMI (and potentially from GOME-2 and SCIAMACHY as well). We also acknowledge that these simulations do not include cloud effects and rotational Raman scattering, which might affect especially retrievals at the $\mathrm{O}_{2} \mathrm{~B}$ band region (Vasilkov et al., 2013).

\subsection{Effects of cloud contamination on SIF retrievals}

The results in Figs. 6 and 8 show that the retrieval is not significantly affected by the atmosphere under clear-sky conditions, especially for NIR fitting windows. However, we expect undetected clouds to be the main source of systematic errors in the retrieval because of the extinction of SIF between the surface and the TOA. As discussed in Sect. 2.2, this effect would manifest itself as a decrease in atmospheric transmittance at the spectral continuum. This is not accounted for by the effective $\boldsymbol{T}_{\uparrow}^{\mathrm{e}}$ in Eq. (3), which is normalized to unity at the continuum, so the retrieval will be low-biased in the presence of sub-pixel clouds.

As mentioned in Sect. 3.1, we have evaluated this effect through simulations of TROPOMI-like TOA radiance spectra including different levels of cloud contamination, represented by the COT at $550 \mathrm{~nm}$. Here we use different COT values as an approximation for different cloud fractions in the measurement. We have also used these simulations to assess the impact of cloud contamination on the retrieval of reflectance-based vegetation indices. The normalized difference vegetation index (NDVI) (Tucker, 1979) has been selected as a reference for such indices. Figure 9 shows the underestimation of SIF and NDVI retrievals for different levels of cloud optical thickness. It can be observed that the effect is generally small for SIF with respect to the NDVI, in line with the findings by Frankenberg et al. (2012), and that it depends strongly on the fitting window for SIF. The effect is smallest for the 745-758 and 681-686 nm windows free from atmospheric lines. The loss of SIF is around $15 \%$ for a COT at $550 \mathrm{~nm}$ of 5 in the $745-758 \mathrm{~nm}$ window, and around $20 \%$ for the $681-686 \mathrm{~nm}$ window, which also reveals an increase of the cloud effect towards shorter wavelengths. The loss of SIF is only slightly larger for the $735-758 \mathrm{~nm}$ window, and becomes largest for the 745-772 nm window around the $\mathrm{O}_{2}$ A-band containing a number of strong atmospheric lines.

The larger impact of clouds on the NDVI can be explained by the fact that NDVI is not only affected by the shielding effect of clouds on the observed pixels, as is the case of SIF, but also from the "whitening" of the reflectance spectrum due to the different spectral impact of clouds on red and NIR wavelengths. This finding suggests a better performance of SIF 


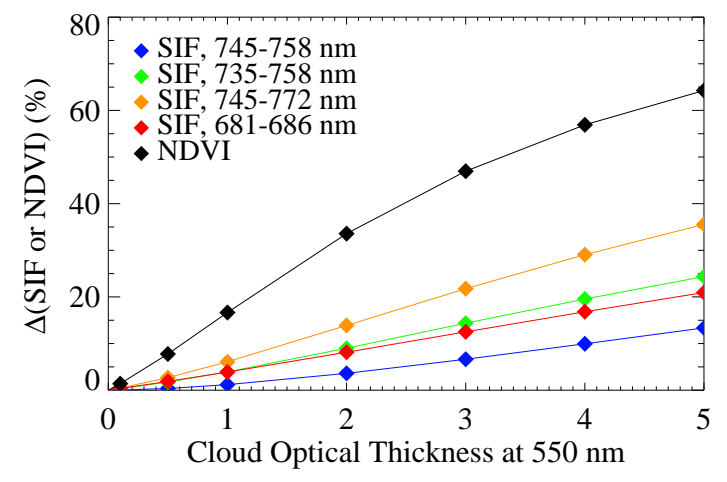

Figure 9. Simulated effect of cloud contamination (represented by cloud optical thickness at $550 \mathrm{~nm}$ ) on retrieved SIF and NDVI. Different retrieval fitting windows are tested in the case of SIF. The $\Delta$ symbol refers to the underestimation of SIF and NDVI under cloudy conditions with respect to the clear-sky case.

than of reflectance-based observations over regions with persistent cloudy skies such as tropical rainforests.

\subsection{Global estimates of retrieval precision}

The results discussed in Sect. 4.1 demonstrate that instrumental noise is the main contribution to the error budget in SIF retrieval for clear-sky observations in the absence of instrumental issues significantly affecting the radiometric performance such as stray light. Here, we give a perspective on how it propagates to spatio-temporal composites of SIF derived from TROPOMI and GOME-2 single retrievals using the simulations described in Sect. 3.2. We select the month of July as study case because the greenness of Northern Hemisphere vegetation peaks at that time, and therefore it is then when we find the largest variability of vegetated areas on the planet.

The resulting global distribution of the number of clearsky observations $n_{\mathrm{m}}$ in a 7-day period in July as well as the SNR at $758 \mathrm{~nm}$ are shown in Fig. 10 for TROPOMI and GOME-2. It can be observed that the number of clear-sky observations is systematically higher for TROPOMI despite the much smaller gridboxes $\left(0.1^{\circ}\right.$ for TROPOMI, $0.5^{\circ}$ for GOME-2). This is the result of three combined effects: (i) the much higher number of measurements per second ( 216 for TROPOMI and 4 for GOME-2, see Table 1), (ii) the higher fraction of clear-sky measurements for smaller pixels (Krijger et al., 2007) and (iii) the slightly higher number of overpasses per day (plotted for TROPOMI in Fig. 5) as a result of the wider swath $(2600 \mathrm{~km}$ for TROPOMI and 1960 for GOME-2). The main difference is in the absolute number of measurements per unit time, which is partly accounted for by the smaller gridboxes for TROPOMI. The resulting SNR at $758 \mathrm{~nm}$ is also generally higher for TROPOMI, especially at low latitudes. This is because of the larger solar irradiance at the $\sim$ 13:00 local overpass time of TROPOMI than at the $\sim$ 09:00 overpass time of GOME-2 (the SNR is however generally larger for GOME- 2 than for TROPOMI at the same radiance level, see Fig. 3).

The standard error of the mean for the spatio-temporal binning of single clear-sky retrievals in the 735-758 nm fitting window is estimated with Eq. (6), $n_{\mathrm{m}}$ in the equation being the total number of clear-sky measurements in Fig. 10. Results are shown in Fig. 11 for the same conditions as those in Fig. 10, except that the measurement time for GOME-2 is set to 13:00 in the simulations in order to compare with TROPOMI under the same illumination conditions. Substantial improvements in TROPOMI can be observed by comparing the resulting standard errors, which are generally about half as large as those for GOME-2 for the configuration selected for these simulations. It can be observed that the standard error is below $0.2 \mathrm{~mW} \mathrm{~m}^{-2} \mathrm{sr}^{-1} \mathrm{~nm}^{-1}$ (about $\sim 10 \%$ of the peak SIF values observed globally) which can be considered a desirable error threshold for global composites of SIF.

The maps in Fig. 12 show the standard errors for TROPOMI and GOME- 2 composites of 7 days and a cloud fraction $<50 \%$, and additionally also for 3 days and $<20 \%$ cloud fraction for TROPOMI, over a region in western Europe in July. These results illustrate the substantial improvement in spatial resolution by TROPOMI and that it will enable clear-sky composites with a more strict cloud screening and smaller temporal bins than GOME-2.

It must be remarked that the aim of these global simulations is to show the potential of TROPOMI for global SIF monitoring with respect to GOME-2, rather than to provide absolute uncertainty figures. These are highly driven by $n_{\mathrm{m}}$ in Eq. (6), and hence by the particular definition of clearsky conditions. We find it difficult to link the MODIS cloud fraction data used in this study (see Sect. 3.2) with a total measure of cloud contamination. In addition, we are working with a conservative SNR curve for TROPOMI, so the results in Figs. 10-12 only represent a worst-case scenario regarding instrumental noise.

\section{Discussion}

\subsection{Validation of SIF retrievals: intercomparison with OCO-2}

Despite the fact that TROPOMI will measure with a much higher spatial resolution than comparable instruments such as GOME-2 and SCIAMACHY, the validation of SIF retrievals in TROPOMI's $7 \mathrm{~km} \times 7 \mathrm{~km}$ pixels through direct comparison with ground-based measurements (typical footprints of the order of $1 \mathrm{~m}$ ) is still challenging. Very homogeneous sites and careful measurement protocols will be needed for such validation experiments, ideally combined with airborne spectroscopic measurements which make it possible to bridge the scaling gap between ground-based 


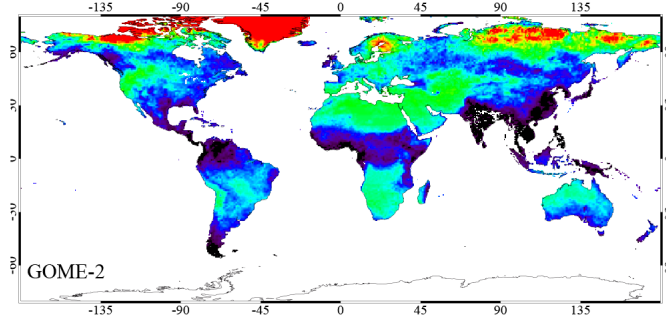

Num. Clear-Sky Observ.
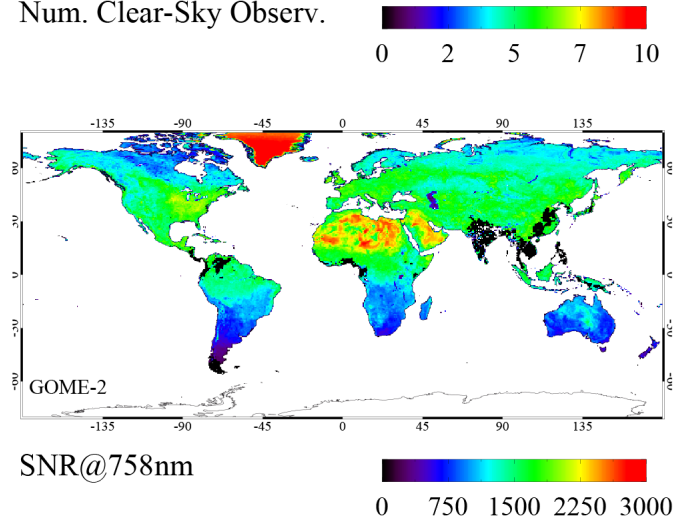

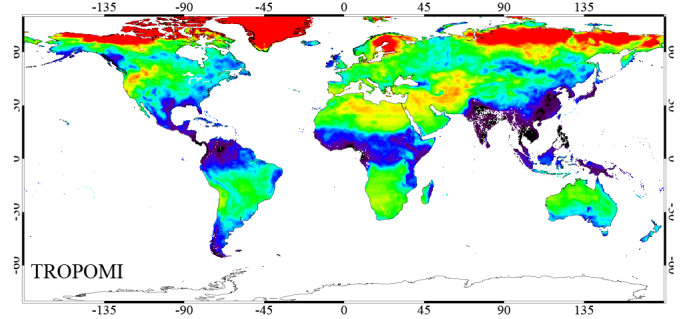

Num. Clear-Sky Observ
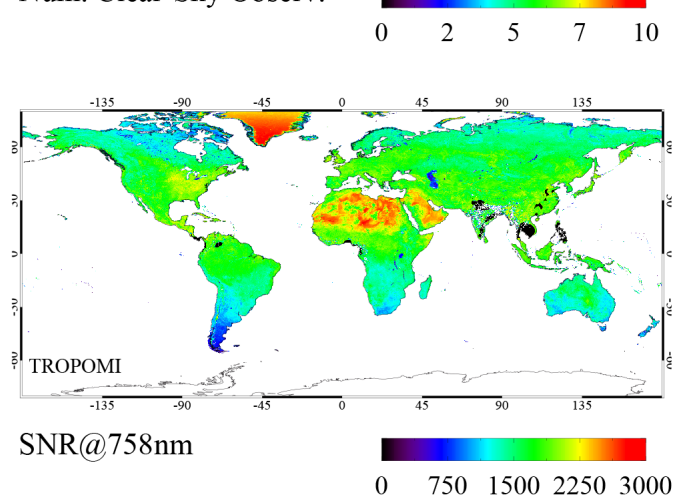

Figure 10. Global composites of total number of clear-sky observations and SNR at $758 \mathrm{~nm}$ for GOME-2 (left column) and TROPOMI (right column). The simulations are for 7-day time averages in July. The overpass time and the gridbox size is $13 \mathrm{~h}$ and $0.1^{\circ}$ for TROPOMI and $9 \mathrm{~h}$ and $0.5^{\circ}$ for GOME-2. Input SNR-radiance curves are shown in Fig. 3. Cloud-free gridboxes are defined as those for which the fraction of cloudy pixel area is $<50 \%$. Black gaps in the maps correspond to areas for which the number of clear-sky observations in the 7-day period is statistically $<1$.
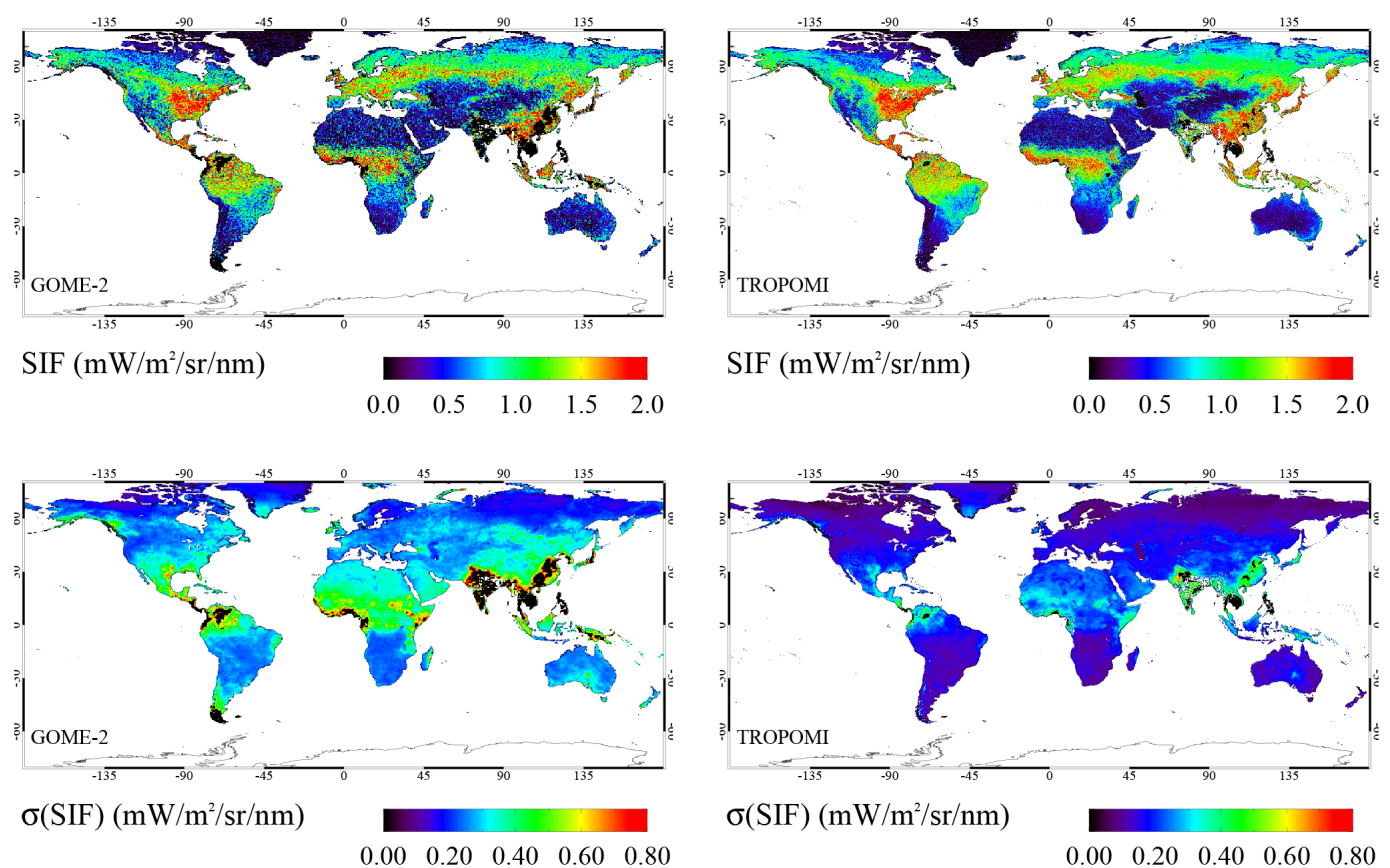

Figure 11. Global composites of mean SIF and standard error of the mean $(\sigma(\mathrm{SIF}))$ for the $735-758 \mathrm{~nm}$ fitting window and the same conditions of Fig. 10, except that the measurement time for GOME-2 is set to $13 \mathrm{~h}$ in order to compare with TROPOMI under the same illumination conditions. 


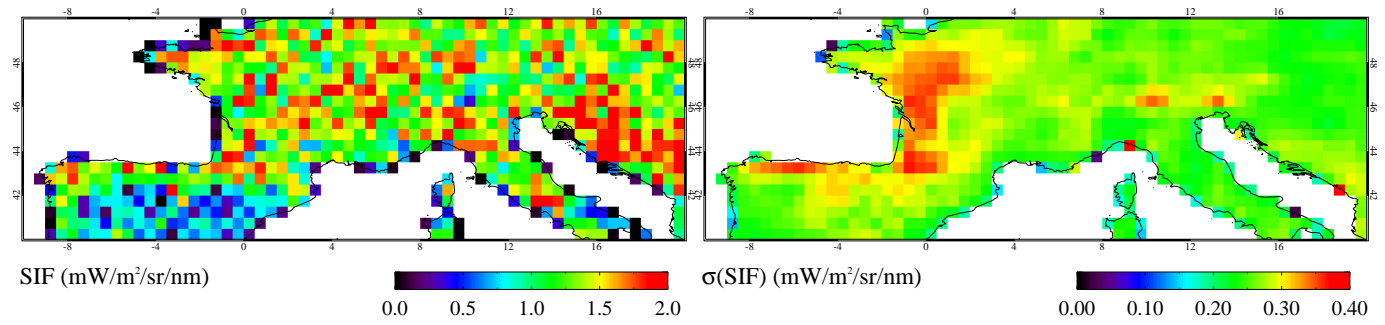

(a) GOME-2, 7-day composite, cloud fraction $<50 \%$

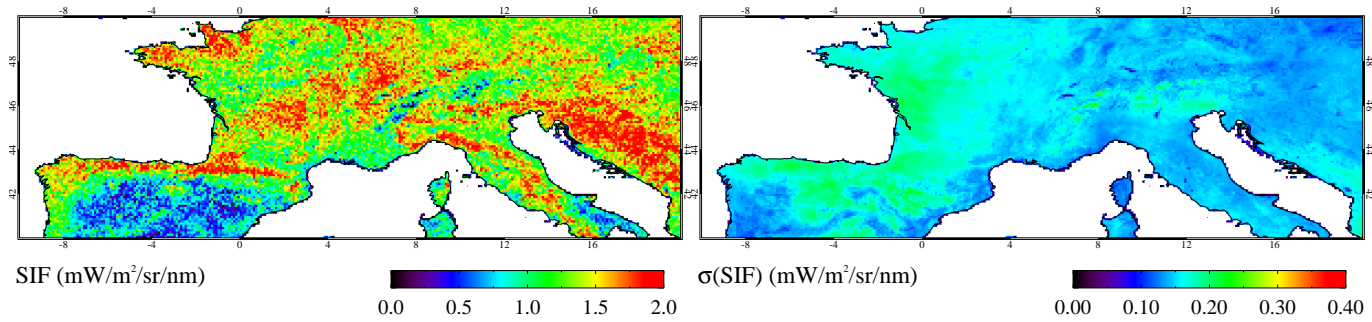

(b) TROPOMI, 7-day composite, cloud fraction $<50 \%$

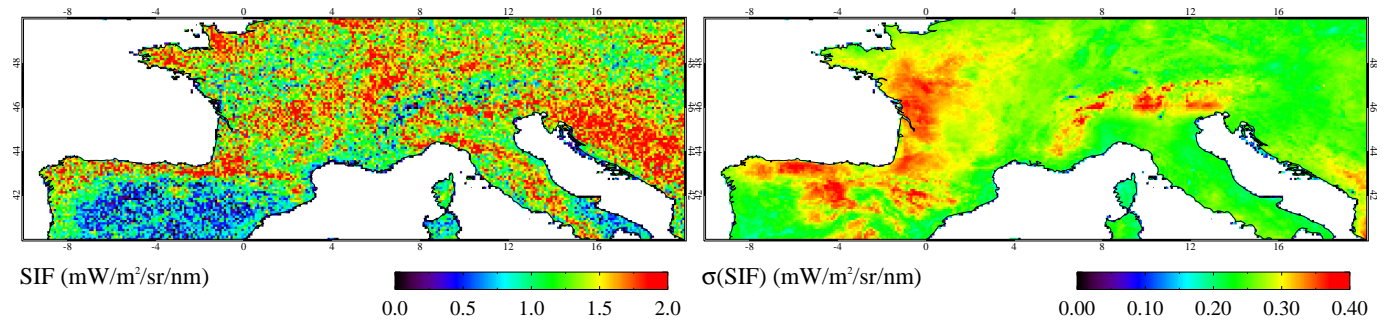

(c) TROPOMI, 3-day composite, cloud fraction $<20 \%$

Figure 12. Composites of mean SIF and standard error of the mean $(\sigma(\mathrm{SIF}))$ for the $735-758 \mathrm{~nm}$ fitting window in July from GOME-2 and TROPOMI for an area in western Europe $\left(40-50^{\circ} \mathrm{N},-10-20^{\circ} \mathrm{E}\right)$. Simulated clear-sky composites are for a 7-day average and a cloud fraction $<50 \%$ for both GOME-2 and TROPOMI, and additionally also for a 3-day average and a cloud fraction $<20 \%$ for TROPOMI.

measurements and satellite-based data sets (Guanter et al., 2007; Rascher et al., 2009; Damm et al., 2014).

As a complement, intercomparisons of SIF products derived from different spaceborne instruments can provide useful information on the consistency of the derived data sets. By the time TROPOMI will fly and collect data, GOME-2, GOSAT and OCO-2 data should be available for direct satellite intercomparisons. In particular, OCO-2 provides a unique opportunity for cross-validation of observed SIF radiances at $758 \mathrm{~nm}$ from TROPOMI as local overpass times are almost identical. TROPOMI will fly in loose formation with JPSS- 1 at an altitude of $824 \mathrm{~km}$ and a local overpass time of $1.30 \mathrm{p} . \mathrm{m}$. In this context, OCO- 2 can be considered a benchmark for two reasons. First, the high spectral resolution $(0.04 \mathrm{~nm}$ FWHM) allows the application of very accurate SIF retrievals using micro-windows and physics-based retrieval algorithms (Frankenberg et al., 2011a; Joiner et al., 2011; Guanter et al., 2012). Second, OCO-2 has a much higher spatial resolution (approx. $3 \mathrm{~km}^{2}$ ground pixel area) such that multiple OCO-2 retrievals can be averaged for comparisons against the $7 \mathrm{~km} \times 7 \mathrm{~km}$ TROPOMI footprint. This is an important aspect as single-measurement noise for SIF retrievals is relatively high and averaging is needed to reduce the standard error.

The comparison procedure will include averaging of OCO-2 to the TROPOMI spatial resolution, followed by a statistical comparison of the two, using OCO-2 as benchmark as it will have been validated against airborne data and will exhibit a much better standard error because spatial averaging will have been performed (the OCO-2 footprint area is about 16 times smaller, this averaging reduces precision errors by a factor of 4). This validation exercise will be performed throughout the time when the two missions coexist in order to exclude instrumental drifts. In addition, barren surfaces with varying reflectances will be used as additional validation standard to study whether any non-linearities of dark current offsets within the instrument cause variable fluorescence values over non-fluorescing targets. Furthermore, 
non-fluorescing targets will be used to also validate the uncertainty estimates by comparing expected with actual standard deviations in retrieved SIF.

\subsection{Towards a global representation of vegetation structure and gross primary production from TROPOMI measurements}

TROPOMI will be the first imaging spectrometer providing a continuous and dense spectral sampling of the red and NIR spectral region at global scale with moderate spatial resolution. Together with the spectral information used for retrievals at the two peaks of the SIF emission spectrum, additional spectral bands are located in the blue (405-495 nm) and short-wave infrared $(2305-2385 \mathrm{~nm})$. This spectral setting makes it possible to derive additional geophysical variables, complementary to SIF, and moving towards a holistic representation of vegetation canopies and a self-contained description of global photosynthesis.

The capability to derive additional vegetation variables such as chlorophyll and water content or LAI is interesting as these variables are important indicators for plant health (Sampson et al., 2003), phenology (Delbart et al., 2005), and facilitate estimates of exchange processes between terrestrial vegetation and the atmosphere (Buermann et al., 2001). Biochemical and structural vegetation variables are also critical to relate SIF observations and gross primary production (GPP, the output from photosynthesis). Although significant relations between SIF and GPP were reported recently (Damm et al., 2010; Frankenberg et al., 2011b; Guanter et al., 2014), they were found to be biome specific (Guanter et al., 2012). This indicates the existence of additional factors impacting these relationships, e.g. canopy structure (Guanter et al., 2012), or stress effects and related interferences of plant protection mechanisms (van der Tol et al., 2009).

The chlorophyll content of vegetation canopies can be extracted from atmospherically corrected surface reflectance data by exploiting contrasting wavelengths in the red-edge spectral region, including the red that is sensitive to chlorophyll absorption and the unaffected NIR. The high spectral sampling of TROPOMI in the red-edge region allows applying various approaches proposed in the literature, for example (i) two- or multiband spectral indices (Zarco-Tejada et al., 2004), (ii) spectral integral approaches (Malenovsky et al., 2013) explicitly requiring high spectral resolution in the spectral interval between 650 and $720 \mathrm{~nm}$, (iii) the position and shape of the red edge (Filella and Peñuelas, 1994), or (iv) machine learning approaches relying mainly on the 680$730 \mathrm{~nm}$ wavelength range for Cab estimates (Verrelst et al., 2013).

The additional SWIR bands of TROPOMI provide the capability to estimate the water content of vegetation canopies. The retrieval of canopy water content is based on atmospherically corrected surface reflectance data in the SWIR, strongly affected by liquid water absorption, and the NIR spectral region being relatively insensitive. Two-band indices such as the Normalized Difference Water Index (NDWI) (Gao, 1996), are applicable to TROPOMI data to obtain the canopy water content in addition to SIF.

The amount of photosynthetic active leaves in a canopy, expressed as LAI, typically impacts the radiative transfer of the 400-2500 nm wavelength range. Several established LAI retrieval approaches focus on the red-edge spectral region instead, while suggested approaches that are potentially applicable for TROPOMI data include (i) empirical indices (Haboudane et al., 2004) based on broader spectral bands around 670 and $800 \mathrm{~nm}$, e.g. the Soil Adjusted Vegetation Index (SAVI) (Huete, 1988) or its derivative MSAVI (Qi et al., 1994) and SARVI (Kaufman and Tanré, 1992), (ii) generic indices located in the red-edge using spectral bands at 674 and $712 \mathrm{~nm}$ (Delegido et al., 2013), or (iii) machine learning approaches being sensitive for spectral bands around 471, 511, 725, and $997 \mathrm{~nm}$ (Verrelst et al., 2012), while TROPOMI covers most of these suggested bands.

Canopy structure impacts the radiative transfer in vegetation canopies and was discussed as a dominant factor driving variations in surface reflectance (Lewis and Disney, 2007). Neglecting structural effects can lead to misinterpretations of reflectance and SIF signals and to spurious correlations between canopy reflectance and estimated geophysical variables (Knyazikhin et al., 2012; Ustin, 2013). Recently, Knyazikhin et al. (2012) proposed the directional area scattering factor (DASF), a remote sensing variable solely related to canopy structure that is even applicable for dense vegetation canopies where reflectance tends to saturate. The application of the DASF provides means to compensate the structural sensitivity of surface reflectance and SIF and provides a strategy to derive vegetation variables with minimized sensitivity to canopy structure. The high spectral resolution of TROPOMI in the $710-775 \mathrm{~nm}$ spectral region makes it possible to retrieve the DASF and with this, additional information on directional scattering effects required for the interpretation of retrieved SIF (Guanter et al., 2014) and structural correction of geophysical variables can be provided (Weyermann et al., 2014).

The geophysical variables discussed above are critical to interpret and relate retrieved SIF to GPP and make it possible to move to a self-contained capability of TROPOMI to globally map GPP. The complexity of interferences between physiological effects and environmental factors (PorcarCastell et al., 2014), however, requires adequate strategies to consistently assimilate and interpret such information sources. In this context, process-based models provide a flexible framework for data assimilation, e.g. the Soil Canopy Observation of Photosynthesis and the Energy balance model (SCOPE) (van der Tol et al., 2009) or the National Center for Atmospheric Research Community Land Model version 4 (NCAR CLM4) (Lawrence et al., 2011). Observation of SIF and other vegetation variables can be potentially used to (i) directly parametrize sub-components of these models 
using values or their respective ranges, (ii) constrain model predictions, or (iii) re-calibrate internal functions.

The self-contained capability of TROPOMI to map photosynthesis will additionally benefit from the envisaged formation flying with NASA's Suomi-NPP (National Polarorbiting Partnership) mission, since this tandem concept provides further critical environmental variables, e.g. surface temperature from the VIIRS (Visible Infrared Imaging Radiometer Suite) instrument.

\section{Conclusions}

In this paper we have discussed the potential of the upcoming S5P/TROPOMI for global monitoring of SIF. By means of a sensitivity analysis we have shown that TROPOMI will enable a substantial improvement in SIF retrieval with respect to existing spaceborne instruments such as GOME-2 and SCIAMACHY, especially thanks to the finer spatial resolution, the much larger number of measurements per day and the higher retrieval sensitivity.

We characterize the precision of global SIF composites with the standard error of the mean, which depends on single-retrieval uncertainty and the number of clearsky measurements per spatio-temporal bin. In general, a $0.2 \mathrm{~mW} \mathrm{~m}^{-2} \mathrm{sr}^{-1} \mathrm{~nm}^{-1}$ value (about $10 \%$ of the peak SIF values observed globally) could be used as an orientative error threshold for the definition of spatio-temporal bins. We arbitrarily choose a $0.1^{\circ}$ latitude/longitude grid to sample the $7 \mathrm{~km} \times 7 \mathrm{~km}$ pixels of TROPOMI. In the time dimension, our simulations show that temporal bins from 3 to 5 days can bring precision below the $0.2 \mathrm{~mW} \mathrm{~m}^{-2} \mathrm{sr}^{-1} \mathrm{~nm}^{-1}$ signal threshold for most of the regions on the planet.

We would like to state that we expect a better retrieval precision for real TROPOMI data because of the conservative SNR-radiance curve used for TROPOMI in this study. On the other hand, the instrument model used in our simulations does not include potential systematic measurement errors, such as from calibration offsets or stray light, which might severely affect SIF retrievals. A more accurate analysis of absolute error figures will be performed when more details on the TROPOMI radiometric and spectral performance become available. Directional effects in the SIF emission, which might affect the quality of spatio-temporal composites when averaging retrievals from the wide range of view angles sampled by TROPOMI, will also be a matter of future research.

We have demonstrated in Sect. 4.2 that most of the SIF signal retrieved from TROPOMI is preserved for moderate levels of cloud contamination, which is in line with the findings by Frankenberg et al. (2012) for higher spectral resolution spectrometers such as GOSAT and OCO-2, and that SIF is less sensitive to cloud contamination than reflectance-based vegetation indices. Cloud fraction thresholds $<40-50 \%$ are being currently used for cloud screening of GOME-2 re- trievals (Joiner et al., 2013; Köhler et al., 2014). In principle, lower levels of cloud contamination would be desirable in order to minimize confounding effects in the interpretation of the resulting SIF products (e.g. region-specific damps of the seasonal cycle). Our results suggest that a more restrictive cloud screening can in fact be allowed for TROPOMI without a drastic increase of the standard error thanks to the much higher number of clear-sky retrievals and the higher retrieval sensitivity.

Another important aspect is the wide spectral window covered by TROPOMI, which facilitates a self-contained description of the canopy physiological and structural condition. On the one hand, we have shown that TROPOMI enables retrievals at different spectral windows covering the two peaks of the SIF emission, which can potentially enhance the physiological information provided by SIF. On the other hand, measurements of spectral reflectance in the so-called vegetation red-edge between the red and NIR regions of the spectral window sampled by TROPOMI are known to provide key information for the characterization of leaf photosynthetic pigment contents and canopy structure. Reflectance-based measurements are much more sensitive to cloud contamination than SIF retrievals, which reinforces the need for strictly cloud-free measurements from TROPOMI and justifies the fact that such parameters are not being derived globally from GOME-2 and SCIAMACHY, for which completely cloud-free observations are in practice not available because of the large pixels.

The launch of S5P/TROPOMI in early 2016 will be very timely given the international Earth Observation scenario for SIF monitoring in the coming years. In addition to the synergy with OCO-2 discussed in this paper, TROPOMI will be the precursor for upcoming spaceborne instruments with similar spectral coverage and resolution. This includes the TEMPO (Tropospheric Emissions: Monitoring of Pollution) and Sentinel-4 geostationary missions (launch scheduled towards the end of the decade in both cases), the Sentinel-5 mission (planned for launch in 2020) with similar capabilities as TROPOMI, and the ESA Earth Explorer Candidate Mission FLEX (Drusch and FLEX Team, 2008) which, if selected for flight, will be the first satellite mission specifically designed for SIF monitoring.

Acknowledgements. This research has been funded by the Emmy Noether Programme of the German Research Foundation (GU 1276/1-1). Jochem Verrelst and Luis Alonso from the University of Valencia are thanked for the reflectance and fluorescence simulations produced in the framework of the ESA FLUSS project. We would also like to thank the Editor and two anonymous reviewers for their helpful comments.

The article processing charges for this open-access publication have been covered by a Research Centre of the Helmholtz Association. 
Edited by: A. Richter

\section{References}

Buermann, W., Dong, J., Zeng, X., Myneni, R., and Dickinson, R.: Evaluation of the utility of satellite-based vegetation leaf area index data for climate simulations, J. Climate, 14, 3536-3550, 2001.

Chance, K. and Kurucz, R.: An improved high-resolution solar reference spectrum for earth's atmosphere measurements in the ultraviolet, visible, and near infrared, J. Quant. Spectrosc. Ra., 111, 1289-1295, doi:10.1016/j.jqsrt.2010.01.036, 2010.

Crisp, D., Atlas, R., Breon, F., Brown, L., Burrows, J., Ciais, P., Connor, B., Doney, S., Fung, I., Jacob, D., Miller, C., O’Brien, D., Pawson, S., Randerson, J., Rayner, P., Salawitch, R., Sander, S., Sen, B., Stephens, G., Tans, P., Toon, G., Wennberg, P., Wofsy, S., Yung, Y., Kuang, Z., Chudasama, B., Sprague, G., Weiss, B., Pollock, R., Kenyon, D., and Schroll, S.: The orbiting carbon observatory (OCO) mission, in: vol. 34 of Advances in Space Research, Pergamon-Elsevier Science Ltd, Oxford, England, 700709, 2004

Damm, A., Elbers, J., Erler, A., Gioli, B., Hamdi, K., Hutjes, R., Kosvancova, M., Meroni, M., Miglietta, F., Moersch, A., Moreno, J., Schickling, A., Sonnenschein, R., Udelhoven, T., van der Linden, S., Hostert, P., and Rascher, U.: Remote sensing of sun-induced fluorescence to improve modeling of diurnal courses of gross primary production (GPP), Global Change Biol., 16, 171-186, 2010.

Damm, A., Guanter, L., Laurent, V., Schaepman, M., Schickling, A., and Rascher, U.: FLD-based retrieval of sun-induced chlorophyll fluorescence from medium spectral resolution airborne spectroscopy data, Remote Sens. Environ., 147, 256-266, 2014.

Delbart, N., Kergoat, L., Le Toan, T., Lhermitte, J., and Picard, G.: Determination of phenological dates in boreal regions using normalized difference water index, Remote Sens. Environ., 97, 26$38,2005$.

Delegido, J., Verrelst, J., Meza, C. M., Rivera, J. P., Alonso, L., and Moreno, J.: A red-edge spectral index for remote sensing estimation of green LAI over agroecosystems, Eur. J. Agron., 46, 42-52, 2013.

Drusch, M. and FLEX Team: FLEX Report for Assessment, ESA SP-1313/4, ESA-ESTEC, Noordwijk, the Netherlands, 2008.

Fell, F. and Fischer, J.: Numerical simulation of the light field in the atmosphere-ocean system using the matrix-operator method, J. Quant. Spectrosc. Ra., 69, 351-388, 2001.

Filella, I. and Peñuelas, J.: The red edge position and shape as indicators of plant chlorophyll content, biomass and hydric status, Int. J. Remote Sens., 15, 1459-1470, 1994.

Frankenberg, C., Butz, A., and Toon, G. C.: Disentangling chlorophyll fluorescence from atmospheric scattering effects in $\mathrm{O} 2 \mathrm{~A}$ band spectra of reflected sun-light, Geophys. Res. Lett., 38, L03801, doi:10.1029/2010GL045896, 2011a.

Frankenberg, C., Fisher, J. B., Worden, J., Badgley, G., Saatchi, S. S., Lee, J.-E., Toon, G. C., Butz, A., Jung, M., Kuze, A., and Yokota, T.: New global observations of the terrestrial carbon cycle from GOSAT: Patterns of plant fluorescence with gross primary productivity, Geophys. Res. Lett., 38, L17706, doi:10.1029/2011GL048738, 2011b.
Frankenberg, C., O’Dell, C., Guanter, L., and McDuffie, J.: Remote sensing of near-infrared chlorophyll fluorescence from space in scattering atmospheres: implications for its retrieval and interferences with atmospheric $\mathrm{CO}_{2}$ retrievals, Atmos. Meas. Tech., 5, 2081-2094, doi:10.5194/amt-5-2081-2012, 2012.

Frankenberg, C., O’Dell, C., Berry, J., Guanter, L., Joiner, J., Köhler, P., Pollock, R., and Taylor, T. E.: Prospects for chlorophyll fluorescence remote sensing from the Orbiting Carbon Observatory-2, Remote Sens. Environ., 147, 1-12, 2014.

Gao, B.: NDWI - A normalized difference water index for remote sensing of vegetation liquid water from space, Remote Sens. Environ., 58, 257-266, 1996.

Guanter, L., Alonso, L., Gómez-Chova, L., Amorós, J., Vila, J., and Moreno, J.: Estimation of solar-induced vegetation fluorescence from space measurements, Geophys. Res. Lett., 34, L08401, doi:10.1029/2007GL029289, 2007.

Guanter, L., Alonso, L., Gómez-Chova, L., Meroni, M., Preusker, R., Fischer, J., and Moreno, J.: Developments for vegetation fluorescence retrieval from spaceborne high-resolution spectrometry in the $\mathrm{O}_{2}-\mathrm{A}$ and $\mathrm{O}_{2}-\mathrm{B}$ absorption bands, J. Geophys. Res.Atmos., 115, D19303, doi:10.1029/2009JD013716, 2010.

Guanter, L., Frankenberg, C., Dudhia, A., Lewis, P. E., GómezDans, J., Kuze, A., Suto, H., and Grainger, R. G.: Retrieval and global assessment of terrestrial chlorophyll fluorescence from GOSAT space measurements, Remote Sens. Environ., 121, 236251, 2012.

Guanter, L., Rossini, M., Colombo, R., Meroni, M., Frankenberg, C., Lee, J.-E., and Joiner, J.: Using field spectroscopy to assess the potential of statistical approaches for the retrieval of suninduced chlorophyll fluorescence from ground and space, Remote Sens. Environ., 133, 52-61, 2013.

Guanter, L., Zhang, Y., Jung, M., Joiner, J., Voigt, M., Berry, J. A., Frankenberg, C., Huete, A. R., Zarco-Tejada, P., Lee, J.E., Moran, M. S., Ponce-Campos, G., Beer, C., Camps-Valls, G., Buchmann, N., Gianelle, D., Klumpp, K., Cescatti, A., Baker, J. M., and Griffis, T. J.: Global and time-resolved monitoring of crop photosynthesis with chlorophyll fluorescence, P. Natl. Acad. Sci., 111, E1327-E1333, 2014.

Haboudane, D., Miller, J., Pattey, E., Zarco-Tejada, P., and Strachan, I.: Hyperspectral vegetation indices and novel algorithms for predicting green LAI of crop canopies: Modeling and validation in the context of precision agriculture, Remote Sens. Environ., 90, 337-352, 2004.

Huete, A.: A soil-adjusted vegetation index (SAVI), Remote Sens. Environ., 25, 295-309, 1988.

Huete, A., Didan, K., Miura, T., Rodriguez, E., Gao, X., and Ferreira, L.: Overview of the radiometric and biophysical performance of the MODIS vegetation indices, Remote Sens. Environ., 83, 195-213, 2002.

Joiner, J., Yoshida, Y., Vasilkov, A. P., Yoshida, Y., Corp, L. A., and Middleton, E. M.: First observations of global and seasonal terrestrial chlorophyll fluorescence from space, Biogeosciences, 8, 637-651, doi:10.5194/bg-8-637-2011, 2011

Joiner, J., Yoshida, Y., Vasilkov, A. P., Middleton, E. M., Campbell, P. K. E., Yoshida, Y., Kuze, A., and Corp, L. A.: Filling-in of near-infrared solar lines by terrestrial fluorescence and other geophysical effects: simulations and space-based observations from SCIAMACHY and GOSAT, Atmos. Meas. Tech., 5, 809-829, doi:10.5194/amt-5-809-2012, 2012. 
Joiner, J., Guanter, L., Lindstrot, R., Voigt, M., Vasilkov, A. P., Middleton, E. M., Huemmrich, K. F., Yoshida, Y., and Frankenberg, C.: Global monitoring of terrestrial chlorophyll fluorescence from moderate-spectral-resolution near-infrared satellite measurements: methodology, simulations, and application to GOME2, Atmos. Meas. Tech., 6, 2803-2823, doi:10.5194/amt-6-28032013, 2013.

Kaufman, Y. and Tanré, D.: Atmospherically resistant vegetation index (ARVI) for EOS-MODIS, IEEE T. Geosci. Remote, 30, 261-270, 1992.

Knyazikhin, Y., Schull, M. A., Stenberg, P., Mottũs, M., Rautiainen, M., Yang, Y., Marshak, A., Latorre Carmona, P., Kaufmann, R. K., Lewis, P., Disney, M. I., Vanderbilt, V., Davis, A. B., Baret, F., Jacquemoud, S., Lyapustin, A., and Myneni, R. B.: Hyperspectral remote sensing of foliar nitrogen content, P. Natl. Acad. Sci., 110, E185-E192, 2012.

Köhler, P., Guanter, L., and Joiner, J.: A linear method for the retrieval of sun-induced chlorophyll fluorescence from GOME-2 and SCIAMACHY data, Atmos. Meas. Tech. Discuss., 7, 12173 12217, doi:10.5194/amtd-7-12173-2014, 2014.

Krijger, J. M., van Weele, M., Aben, I., and Frey, R.: Technical Note: The effect of sensor resolution on the number of cloud-free observations from space, Atmos. Chem. Phys., 7, 2881-2891, doi:10.5194/acp-7-2881-2007, 2007.

Lawrence, D. M., Oleson, K. W., Flanner, M. G., Thornton, P. E., Swenson, S. C., Lawrence, P. J., Zeng, X., Yang, Z.-L., Levis, S., Sakaguchi, K., Bonan, G. B., and Slater, A. G.: Parameterization Improvements and Functional and Structural Advances in Version 4 of the Community Land Model, J. Adv. Model. Earth Syst., 3, M03001, doi:10.1029/2011MS000045, 2011.

Lewis, P. and Disney, M.: Spectral invariants and scattering across multiple scales from within-leaf to canopy, Remote Sens. Environ., 109, 196-206, 2007.

Malenovsky, Z., Homolova, L., Zurita-Milla, R., Lukes, P., Kaplan, V., Hanus, J., Gastellu-Etchegorry, J.-P., and Schaepman, M. E.: Retrieval of spruce leaf chlorophyll content from airborne image data using continuum removal and radiative transfer, Remote Sens. Environ., 131, 85-102, 2013.

Miller, J. R., Berger, M., Goulas, Y., Jacquemoud, S., Louis, J., Mohammed, G., Moise, N., Moreno, J., Moya, I., Pedrós, R., Verhoef, W., and Zarco-Tejada, P.: Development of a Vegetation Fluorescence Canopy Model, Final report, ESTEC Contract No. 16365/02/NL/FF, ESA-ESTEC, Noordwijk, the Netherlands, 2005.

Plascyk, J. A. and Gabriel, F. C.: The Fraunhofer Line Discriminator MKII - An airborne instrument for precise and standardized ecological luminescence measurement, IEEE T. Instrum. Meas., IM-24, 306-313, 1975.

Porcar-Castell, A., Tyystjärvi, E., Atherton, J., van der Tol, C., Flexas, J., Pfündel, E. E., Moreno, J., Frankenberg, C., and Berry, J. A.: Linking chlorophyll- $a$ fluorescence to photosynthesis for remote sensing applications: mechanisms and challenges, J. Exp. Bot., 65, 4065-4095, doi:10.1093/jxb/eru191, 2014.

Qi, J., Chehbouni, A., Huete, A., Kerr, Y., and Sorooshian, S.: A modified soil adjusted vegetation index, Remote Sens. Environ., 48, 119-126, 1994.

Rascher, U., Agati, G., Alonso, L., Cecchi, G., Champagne, S., Colombo, R., Damm, A., Daumard, F., de Miguel, E., Fernandez, G., Franch, B., Franke, J., Gerbig, C., Gioli, B., Gómez, J. A.,
Goulas, Y., Guanter, L., Gutiérrez-de-la-Cámara, Ó., Hamdi, K., Hostert, P., Jiménez, M., Kosvancova, M., Lognoli, D., Meroni, M., Miglietta, F., Moersch, A., Moreno, J., Moya, I., Neininger, B., Okujeni, A., Ounis, A., Palombi, L., Raimondi, V., Schickling, A., Sobrino, J. A., Stellmes, M., Toci, G., Toscano, P., Udelhoven, T., van der Linden, S., and Zaldei, A.: CEFLES2: the remote sensing component to quantify photosynthetic efficiency from the leaf to the region by measuring sun-induced fluorescence in the oxygen absorption bands, Biogeosciences, 6, 11811198, doi:10.5194/bg-6-1181-2009, 2009.

Sampson, P., Zarco-Tejada, P., Mohammed, G., Miller, J., and Noland, T.: Hyperspectral remote sensing of forest condition: Estimating chlorophyll content in tolerant hardwoods, Forest Science, 49, 381-391, 2003.

Sanders, A. F. J. and de Haan, J. F.: Retrieval of aerosol parameters from the oxygen A band in the presence of chlorophyll fluorescence, Atmos. Meas. Tech., 6, 2725-2740, doi:10.5194/amt-62725-2013, 2013.

Sioris, C. E., Courrèges-Lacoste, G. B., and Stoll, M. P.: Filling in of Fraunhofer lines by plant fluorescence: Simulations for a nadir-viewing satellite-borne instrument, J. Geophys. Res.Atmos., 108, L4133, doi:10.1029/2001JD001321, 2003.

Tucker, C. J.: Red and photographic infrared linear combinations for monitoring vegetation, Remote Sens. Environ., 8, 127-150, 1979.

Ustin, S. L.: Remote sensing of canopy chemistry, P. Natl. Acad. Sci., 110, 804-805, 2013.

van der Tol, C., Verhoef, W., Timmermans, J., Verhoef, A., and Su, Z.: An integrated model of soil-canopy spectral radiances, photosynthesis, fluorescence, temperature and energy balance, Biogeosciences, 6, 3109-3129, doi:10.5194/bg-6-3109-2009, 2009.

Vasilkov, A., Joiner, J., and Spurr, R.: Note on rotational-Raman scattering in the $\mathrm{O}_{2}$ A- and B-bands, Atmos. Meas. Tech., 6 , 981-990, doi:10.5194/amt-6-981-2013, 2013.

Veefkind, J., Aben, I., McMullan, K., Förster, H., de Vries, J., Otter, G., Claas, J., Eskes, H., de Haan, J., Kleipool, Q., van Weele, M., Hasekamp, O., Hoogeveen, R., Landgraf, J., Snel, R., Tol, P., Ingmann, P., Voors, R., Kruizinga, B., Vink, R., Visser, H., and Levelt, P.: TROPOMI on the ESA Sentinel-5 Precursor: A GMES mission for global observations of the atmospheric composition for climate, air quality and ozone layer applications, Remote Sens. Environ., 120, 70-83, 2012.

Verrelst, J., Munoz, J., Alonso, L., Delegido, J., Pablo Rivera, J., Camps-Valls, G., and Moreno, J.: Machine learning regression algorithms for biophysical parameter retrieval: Opportunities for Sentinel-2 and -3, Remote Sens. Environ., 118, 127-139, 2012.

Verrelst, J., Alonso, L., Rivera Caicedo, J. P., Moreno, J., and Camps-Valls, G.: Gaussian Process Retrieval of Chlorophyll Content From Imaging Spectroscopy Data, IEEE J. Select. Top. Appl. Earth Obs. Rem. S., 6, 867-874, 2013.

Weyermann, J., Damm, A., Kneubuehler, M., and Schaepman, M. E.: Correction of Reflectance Anisotropy Effects of Vegetation on Airborne Spectroscopy Data and Derived Products, IEEE T. Geosci. Remote, 52, 616-627, 2014.

Zarco-Tejada, P., Miller, J., Morales, A., Berjon, A., and Aguera, J.: Hyperspectral indices and model simulation for chlorophyll estimation in open-canopy tree crops, Remote Sens. Environ., 90, 463-476, 2004. 